\title{
Interleukin-1 receptor antagonist mediates type I interferon-driven susceptibility to
}

\section{Mycobacterium tuberculosis}

Daisy X. Ji ${ }^{1}$, Katherine J. Chen ${ }^{1}$, Naofumi Mukaida ${ }^{2}$, Igor Kramnik ${ }^{3}$, K. Heran Darwin ${ }^{4}$, Russell E. Vance ${ }^{1,5,6^{*}}$

${ }^{1}$ Division of Immunology and Pathogenesis, Department of Molecular and Cell Biology, University of California, Berkeley, CA 94720 USA

${ }^{2}$ Division of Molecular Bioregulation, Cancer Research Institute, Kanazawa University, Kakuma-machi, Kanazawa 920-1192, Japan

${ }^{3}$ The National Emerging Infectious Diseases Laboratory, Department of Medicine (Pulmonary Center), and Department of Microbiology，Boston University School of Medicine, Boston, MA 02118 USA

${ }^{4}$ Department of Microbiology, New York University School of Medicine, New York, New York, 10016 USA

${ }^{5}$ Cancer Research Laboratory, University of California, Berkeley, CA 94720 USA

${ }^{6}$ Howard Hughes Medical Institute, University of California, Berkeley, CA 94720 USA

*e-mail: rvance@berkeley.edu 


\section{Abstract}

2 The bacterium Mycobacterium tuberculosis (Mtb) causes tuberculosis (TB) and is

3 responsible for more human mortality than any other single pathogen ${ }^{1}$. Although $\sim 1.7$

4 billion people are infected with $M t b^{2}$, most infections are asymptomatic. Progression to

5 active disease occurs in $\sim 10 \%$ of infected individuals and is predicted by an elevated type

6 I interferon (IFN) response ${ }^{3-8}$. Type I IFNs are vital for antiviral immunity, but whether

7 or how they mediate susceptibility to $M t b$ has been difficult to study, in part because the

8 standard C57BL/6 (B6) mouse model does not recapitulate the IFN-driven disease that

9 appears to occur in humans ${ }^{3-5,8}$. Here we examined B6.Sst $1^{S}$ congenic mice that carry the

$10 \mathrm{C} 3 \mathrm{H}$ "sensitive" allele of the Sst 1 locus that renders them highly susceptible to Mtb

11 infections ${ }^{9,10}$. We found that B6.Sst $1^{S}$ mice exhibit markedly increased type I IFN

12 signaling, and that type I IFNs were required for the enhanced susceptibility of B6.Sst ${ }^{S}$

13 mice to $M t b$. Type I IFNs affect the expression of hundreds of genes, several of which

14 have previously been implicated in susceptibility to bacterial infections ${ }^{11,12}$. Nevertheless,

15 we found that heterozygous deficiency in just a single IFN target gene, IL-1 receptor

16 antagonist (IL-1Ra), is sufficient to reverse IFN-driven susceptibility to $M t b$. As even a

17 partial reduction in IL-1Ra levels led to significant protection, we hypothesized that IL-

18 1Ra may be a plausible target for host-directed anti-TB therapy. Indeed, antibody-

19 mediated neutralization of IL-1Ra provided therapeutic benefit to $M t b$-infected B6.Sst ${ }^{S}$

20 mice. Our results illustrate how the diversity of inbred mouse strains can be exploited to

21 better model human TB, and demonstrate that IL-1Ra is an important mediator of type I

22 IFN-driven susceptibility to $M t b$ infections in vivo. 


\section{Introduction}

24 Mycobacterium tuberculosis (Mtb) infects approximately one quarter of all humans

25 worldwide ${ }^{2}$, with highly diverse outcomes ranging from asymptomatic lung granulomas

26 to lethal disseminated disease. Active TB disease is characterized by the uncontrolled

27 replication of bacteria and pathological inflammation in the lungs and other organs, and

28 arises in approximately $10 \%$ of infected HIV-negative individuals. There is no vaccine

29 that reliably protects against pulmonary TB, and although antibiotics can be curative, the

30 long ( $\geq 6$-month) course of treatment and increasing prevalence of multi-drug resistant

$31 M t b$ infections has spurred a search for alternative therapeutic approaches ${ }^{13,14}$. Since only

32 individuals with active TB readily transmit infection, and as humans are the only natural

33 reservoir of $M t b$, a favored strategy to contain the TB epidemic is to identify and treat

34 latently infected individuals likely to progress to active disease ${ }^{1,3}$. Identification of such

35 individuals is challenging, but recent studies have demonstrated that an enhanced type I

36 interferon (IFN) signature correlates with active $\mathrm{TB}^{5,6,8}$ and can predict progression to

37 active TB up to 18 months prior to diagnosis ${ }^{3,4}$. A partial loss-of-function polymorphism

38 in the type I IFN receptor (IFNAR1) is associated with resistance to TB in humans,

39 suggesting that elevated levels of type I IFNs not only predict but may even be causally

40 linked to TB progression ${ }^{15}$. In addition, numerous animal studies have demonstrated

41 causal roles for type I IFNs in susceptibility to $M t b^{6,7,16,17}$ and other bacterial

42 infections $^{11,12}$.

43 Given strong evidence that type I IFNs confer susceptibility to human TB, two

44 major remaining challenges are: (1) to determine the mechanisms by which type I IFNs

45 mediate susceptibility to active TB, and (2) to exploit this knowledge to develop

46 interventions that can reverse the susceptibility. Mechanistic studies and initial trials of

47 possible therapeutic interventions require a robust animal model. However, the most

48 commonly used animal model, the C57BL/6 (B6) mouse, does not robustly recapitulate

49 the interferon-driven TB susceptibility seen in humans. B6 Ifnar ${ }^{-1-}$ mice show mild

50 resistance to $M t b$ in the spleen and variable but modest effects in the lungs ${ }^{18-20}$. To better

51 model IFN-driven susceptibility, some investigators treat $M t b$-infected B6 mice with

52 poly-IC, a potent inducer of type I IFNs ${ }^{21}$. Such treatment dramatically increases

53 susceptibility to $M t b$ in an Ifnar-dependent manner ${ }^{21,22}$, but because the IFN is induced 
54 artificially and not by $M t b$ itself, it is unclear if poly-IC mimics the course of IFN-driven

55 disease in humans.

56 As an alternative approach, we sought to exploit the natural diversity of available

57 inbred mouse strains. The 129 mouse strain shows clear IFN-driven susceptibility to

$58 M t b^{23}$, but there are limited tools on this genetic background. We therefore turned to a

59 previously described congenic mouse strain, B6.Sst $1^{S}$, that carries the $10.7 \mathrm{Mb}$ 'super

60 susceptibility to tuberculosis 1' region of mouse chromosome 1 from $\mathrm{C} 3 \mathrm{H}$ on an

61 otherwise B6 genetic background ${ }^{9,10}$. The B6.Sst $1^{S}$ mice exhibit marked susceptibility to

62 aerosol TB infection ${ }^{9,10}$, however the mechanism by which the $\operatorname{Sst} 1^{S}$ locus confers

63 susceptibility remains incompletely understood. Recent work has established that

64 macrophages from B6.Sst $1^{S}$ mice exhibit an enhanced type I IFN response ${ }^{24,25}$. Here we

65 show that B6.Sst ${ }^{S}$ mice exhibit an exacerbated type I IFN response in vivo that causes

66 susceptibility to $M t b$ infection. We exploit this model of type I IFN-driven TB disease to

67 identify the interleukin-1 receptor antagonist (IL-1Ra) as a major driver of type I IFN-

68 induced susceptibility to $M t b$. Genetic or antibody-mediated reduction in IL-1Ra levels

69 largely eliminates the IFN-induced susceptibility of B6.Sst $1^{S}$ mice. Our results suggest

70 new therapeutic strategies for tuberculosis.

\section{Results}

73 In agreement with previous work ${ }^{24,25}$, we found that bone marrow-derived macrophages

74 (BMMs) from B6.Sst $1^{S}$ mice expressed higher levels of interferon-beta (Ifnb) and

75 interferon-stimulated genes (ISGs) upon stimulation with TNF (Fig. S1). To determine if

76 B6.Sst $I^{S}$ mice also exhibit an enhanced type I IFN signature in vivo, we measured Ifnb

77 transcripts in the lungs of M. tuberculosis-infected mice. Indeed, B6.Sst $1^{S}$ mice exhibited

78 higher levels of Ifnb transcripts as compared to B6 mice (Fig. 1a). To investigate whether

79 this enhanced type I IFN signaling causes the susceptibility of B6.Sst $1^{S}$ mice to Mtb, we

80 infected mice with $M t b$ and then treated with an IFNAR1-blocking antibody ${ }^{26}$ to inhibit

81 type I IFN signaling. B6.Sst $1^{S}$ mice treated with the IFNAR1-blocking antibody showed

82 significantly decreased bacterial burdens compared to those that only received an isotype

83 control antibody (Fig. 1b). To provide genetic confirmation of this result, we crossed

84 B6.Sst $1^{S}$ mice to B6.Ifnar ${ }^{-/-}$mice. Ifnar deficiency largely reversed the enhanced

85 susceptibility of B6.Sst ${ }^{S}$ mice to $M t b$ infection. At 25 days post-infection, the bacterial 
bioRxiv preprint doi: https://doi.org/10.1101/389288; this version posted August 10, 2018. The copyright holder for this preprint (which was not certified by peer review) is the author/funder, who has granted bioRxiv a license to display the preprint in perpetuity. It is made available under

a aCC-BY 4.0 International license.

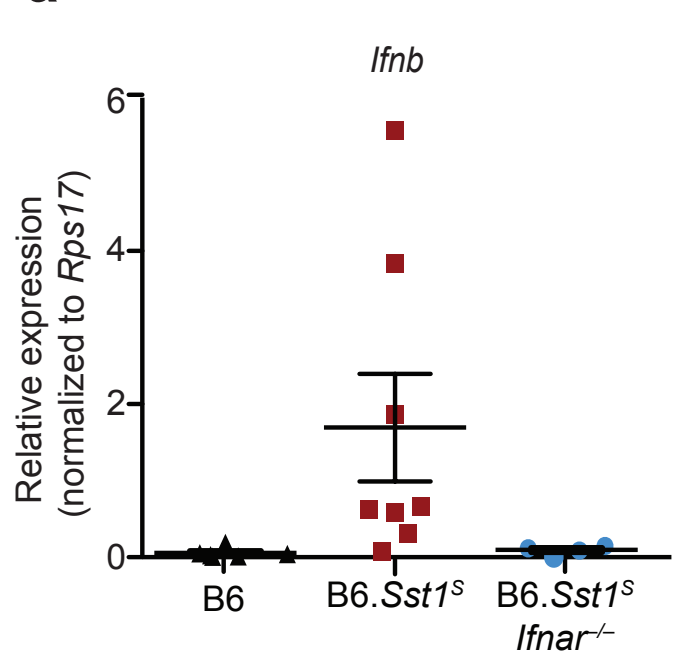

C

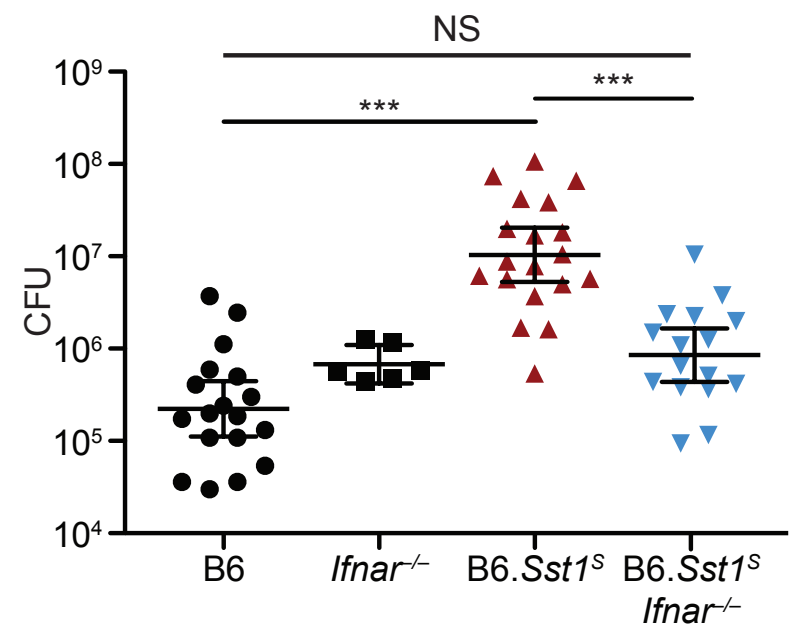

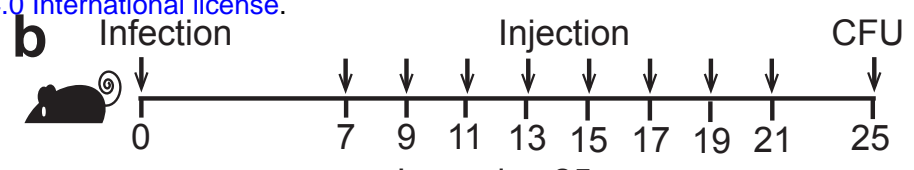

Lung day 25

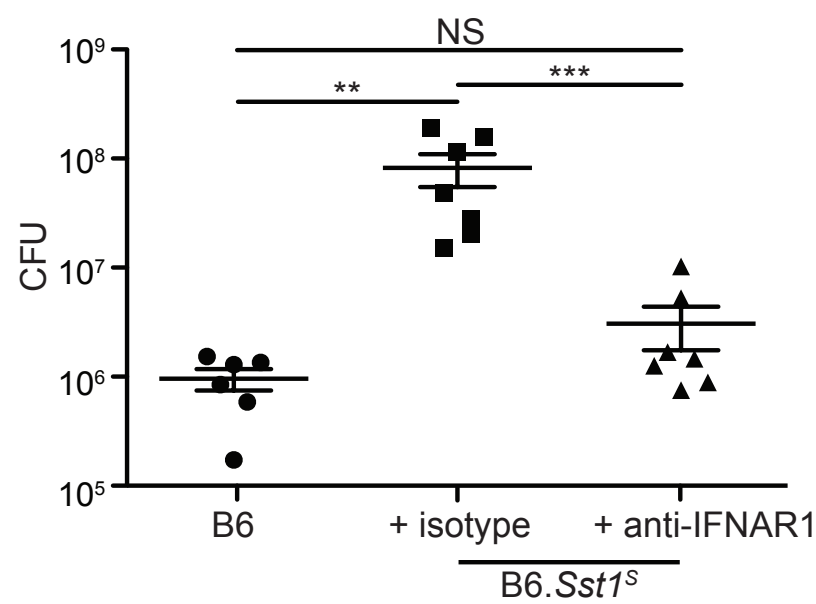

d

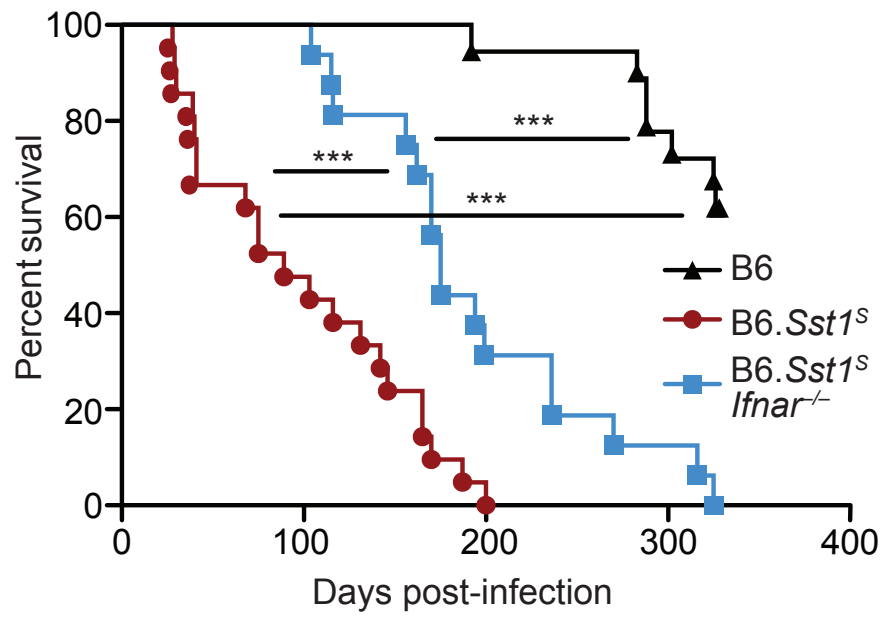

Fig. 1 | Type I IFN drives enhanced susceptibility of B6.Sst1s mice. a, Expression of Ifnb measured by qRTPCR relative to Rps17 in Mtb-infected lungs at day 25. b. Lung bacterial burdens at day 25 from Mtb-infected mice treated with anti-IFNAR1 or isotype control antibody. c, Lung bacterial burdens at day 25, or d, survival, of $M t b$-infected mice. For a-c, genotypes indicated on the $\mathrm{x}$-axis. c-d, Combined results from three independent infections. All except B6 mice were bred in-house (b-d). Error bars are SEM. Analyzed with two-ended Mann-Whitney test (b, $\mathbf{c})$ or Log-rank (Mantel-Cox) Test (c). Asterisk, $p \leq 0.05$; two asterisks, $p \leq 0.01$; three asterisks, $p \leq$ 0.001 . 
86 burdens in the lungs of the B6.Sst ${ }^{S}$ Ifnar ${ }^{-/-}$mice were significantly lower than in the

87 lungs of B6.Sst $1^{S}$ mice, and were similar to B6 mice (Fig. 1c). Infected B6.Sst1 ${ }^{S}$ Ifnar ${ }^{-1-}$

88 mice also survived significantly longer than B6.Sst $1^{S}$ mice (Fig. 1d), though there are also

89 clearly Ifnar-independent effects of the $S s t 1^{S}$ locus that act at later time points. By

90 contrast, and consistent with prior reports ${ }^{18-20}$, Ifnar deficiency had little or no effect on

$91 M t b$ disease in wild-type B6 $\left(S s t 1^{R}\right)$ mice. Recent data have suggested that the host

92 protein STING is required for interferon induction to $M t b^{27-31}$. However, crossing

93 B6.Sst $1^{S}$ mice to STING-deficient Sting ${ }^{g t / g t}$ mice did not significantly reduce bacterial

94 burdens at day 25 compared to B6.Sst $1^{S}$ mice (Fig. S2a). However, the B6.Sst $1^{S}$ Sting ${ }^{g t / g t}$

95 mice did show a slight improvement in survival not seen in the B6 genetic background ${ }^{30}$

96 (Fig. S2b). Overall our data demonstrate that the $S s t 1^{S}$ locus acts to increase type I IFN

97 signaling in vivo and thereby exacerbate $M t b$ infection, particularly during the early

98 phases of infection.

Type I IFN negatively regulates anti-bacterial immune responses via multiple mechanisms ${ }^{6,7}$, including through increased IL-10 levels ${ }^{32}$, decreased IFN $\gamma$ signaling ${ }^{33}$,

101 induction of cholesterol 25-hydroxylase $(C h 25 h)^{34}$, and/or decreased IL-1 levels ${ }^{35,36}$. We

102 did not observe significant differences in IL-10 or IFN $\gamma$ levels in the lung during in vivo

$103 M t b$ infection (Fig. S3a,b). In addition, crossing B6.Sst $1^{S}$ mice to B6.Ch $25 h^{-/-}$mice did

104 not alter day 25 lung bacterial burdens (Fig. S3c). Moreover, despite clear evidence that

105 type I IFN and IL-1 counter-regulate each other ${ }^{37}$, the $S s t 1^{S}$ locus did not appear to act to

106 decrease the levels of IL-1 in vivo; in fact, we unexpectedly observed higher levels of

107 both IL-1 $\alpha$ and IL-1 $\beta$ in the lungs of B6.Sst $1^{S}$ mice at 25 days post-infection as compared

108 to B6 mice (Fig. 2a,b). Other inflammatory cytokines, including TNF and CXCL1 were

109 similarly elevated in the B6.Sst $1^{S}$ mice (Fig. S3d,e) as was the frequency of

$110 \mathrm{CD} 1 \mathrm{~b}^{+} \mathrm{Ly}_{6 \mathrm{G}^{+}}$cells (neutrophils) in the lungs (Fig. S3f). The elevated inflammation in

111 B6.Sst $1^{S}$ mice was a consequence of elevated type I IFNs, as inflammatory cytokines and

112 neutrophils were reduced in B6.Sst $1^{S}$ Ifnar $^{-/-}$mice, but the underlying mechanism was not

113 apparent.

114 We reasoned that the high levels of IL-1 $\alpha / \beta$ in B6.Sst $1^{S}$ mice may be a

115 consequence of the higher bacterial burdens in these mice, or alternatively, may be

116 causing increased bacterial replication via induction of a pro-bacterial inflammatory

117 milieu, as previously proposed ${ }^{38,39}$. To distinguish these possibilities, we inhibited IL-1 
bioRxiv preprint doi: https://doi.org/10.1101/389288; this version posted August 10, 2018. The copyright holder for this preprint (which was not certified by peer review) is the author/funder, who has granted bioRxiv a license to display the preprint in perpetuity. It is made available under

a

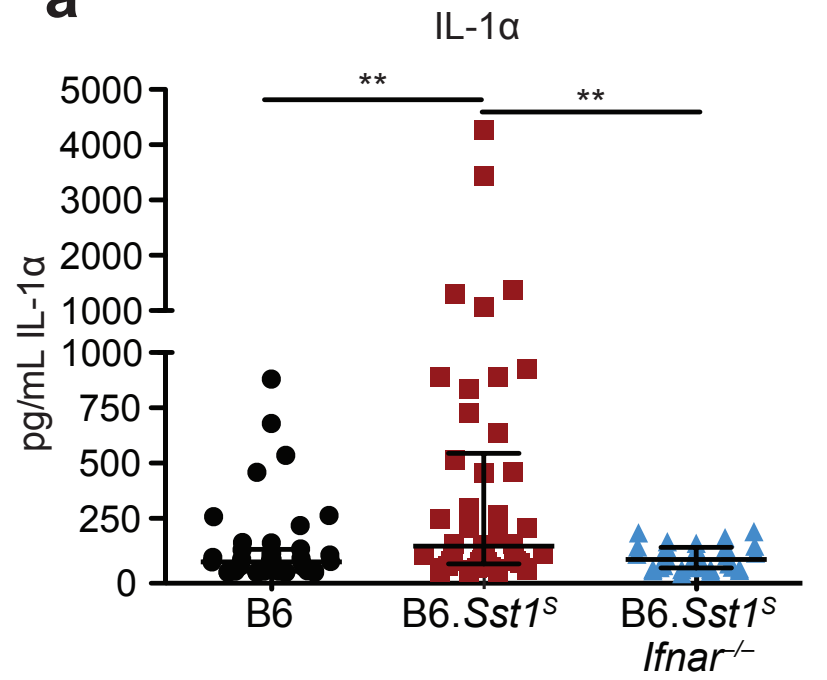

b

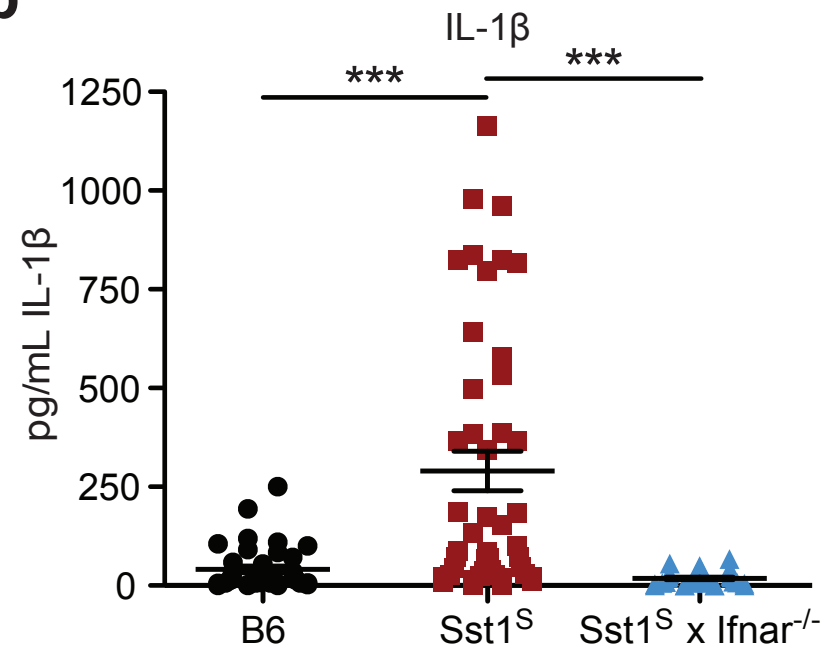

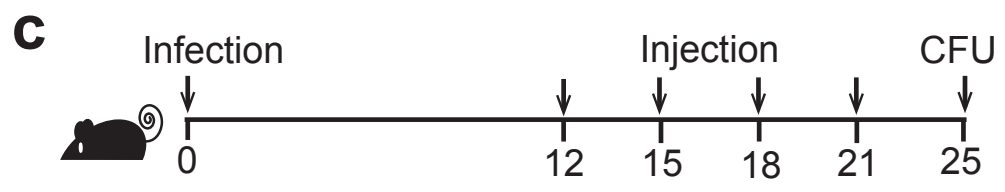

Lung day 25

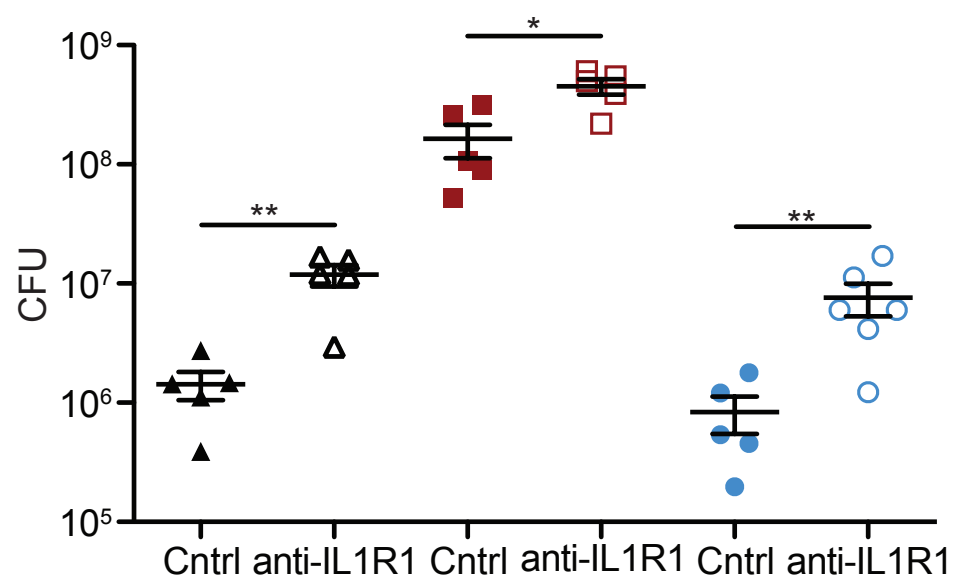

B6

$\overline{\text { B6.Sst1s }}$

B6.Sst1s

Ifnar ${ }^{-1}$

Fig. 2 | IFNAR signaling results in high but non-pathological IL-1 protein levels in B6.Sst1s mice. a-b, Protein levels of IL-1 $\alpha(\mathbf{a})$ and IL-1 $\beta$ (b) were measured in the lungs of $M t b$-infected mice by ELISA at day 25. Combined results of four independent experiments. c, Lung bacterial burdens at day 25 from $M$ tb-infected mice treated with anti-IL1R1 or isotype control antibody. All animals except B6 were bred in-house (a-c). Error bars are SEM. Analyzed with two-ended Mann-Whitney test (a-c). Asterisk, $p \leq 0.05$; two asterisks, $p \leq 0.01$; three asterisks, $p \leq 0.001$. 
118 signaling in vivo using an anti-IL-1R1 blocking antibody ${ }^{40}$, beginning 12 days post-

119 infection (Fig. 2c, S4a). Both B6 and B6.Sst $1^{S}$ mice treated with IL-1R1 blocking

120 antibody exhibited increased bacterial burdens compared to mice treated with an isotype

121 control antibody. These results confirm prior evidence that IL-1 plays a protective role in

122 B6 mice ${ }^{41-46}$, and extend this observation to B6.Sst $1^{S}$ mice as well. Thus, elevated IL-1

123 levels do not explain the exacerbated infections of B6.Sst $1^{S}$ mice.

124 Type I IFNs induce the expression of hundreds of target genes. However, given

125 that IL-1 signaling is essential for resistance to $M t b^{41,42}$, we were particularly interested in

126 Illrn, which encodes the secreted IL-1 receptor antagonist (IL-1Ra) ${ }^{47}$. IL-1Ra binds to

127 IL-1R1 without generating a signal and blocks binding of both IL- $1 \alpha$ and IL-1 $\beta^{48}$ (Fig.

$1283 \mathrm{a}$ ). Il1rn is known to be induced by type I IFN signaling ${ }^{49,50}$, and as expected, B6.Sst ${ }^{S}$

129 BMMs strongly upregulated Illrn in an Ifnar-dependent manner when stimulated with

130 TNF (Fig. 3b). Similarly, B6.Sst $1^{S}$ mice infected with $M$. tuberculosis had higher levels

131 of IL-1Ra protein in their lungs, as compared to infected B6 or B6.Sst $1^{S}$ Ifnar ${ }^{-1-}$ mice

132 (Fig. 3c, S4b). These results raised the possibility that the high IL-1 protein levels in

133 B6.Sst $1^{S}$ mice are inadequate to protect against infection because of a block in IL-1

134 signaling. To test this possibility, we examined the amount of functional IL-1 signaling in

135 lung homogenates from infected mice using HEK-Blue-IL-1R ${ }^{\mathrm{TM}}$ reporter cells

136 (Invivogen). Despite higher levels of IL-1 proteins, lung homogenates from infected

137 B6.Sst $1^{S}$ mice had less functional IL-1 signaling capacity as compared with B6 mice (Fig.

$1383 \mathrm{~d}, \mathrm{~S} 3 \mathrm{c})$. The reporter appeared to be a reliable indicator of functional IL-1 as responses

139 were blocked by anti-IL-1R1 antibody (Fig. S4c). The lower levels of IL-1 signaling seen

140 in B6.Sst $1^{S}$ mice was reversed in B6.Sst $1^{S}$ Ifnar ${ }^{-1-}$ mice. These data underline the

141 importance of distinguishing IL-1 protein levels from signaling capacity, and suggest that

142 B6.Sst $I^{S}$ mice may be susceptible to $M t b$ because of reduced functional IL-1 signaling,

143 despite increased IL-1 protein levels. Consistent with these observations, some data

144 suggest IL-1Ra may also exacerbate TB in humans ${ }^{51-54}$.

145 To test whether excessive type I IFN signaling neutralizes IL-1 signaling via IL-

146 1Ra, we sought to reduce IL-1Ra levels in B6.Sst ${ }^{S}$ mice during $M t b$ infection. To do

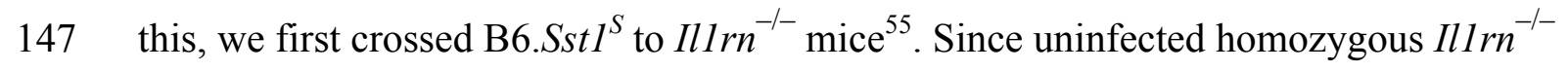

148 mice exhibit signs of inflammatory disease due to dysregulated IL-1 signaling ${ }^{55,56}$, and

149 because heterozygous $I l 1 r^{+/-}$mice have a partial decrease in IL-1Ra levels ${ }^{55}$, we 
bioRxiv preprint doi: https://doi.org/10.1101/389288; this version posted August 10, 2018. The copyright holder for this preprint (which was not certified by peer review) is the author/funder, who has granted bioRxiv a license to display the preprint in perpetuity. It is made available under
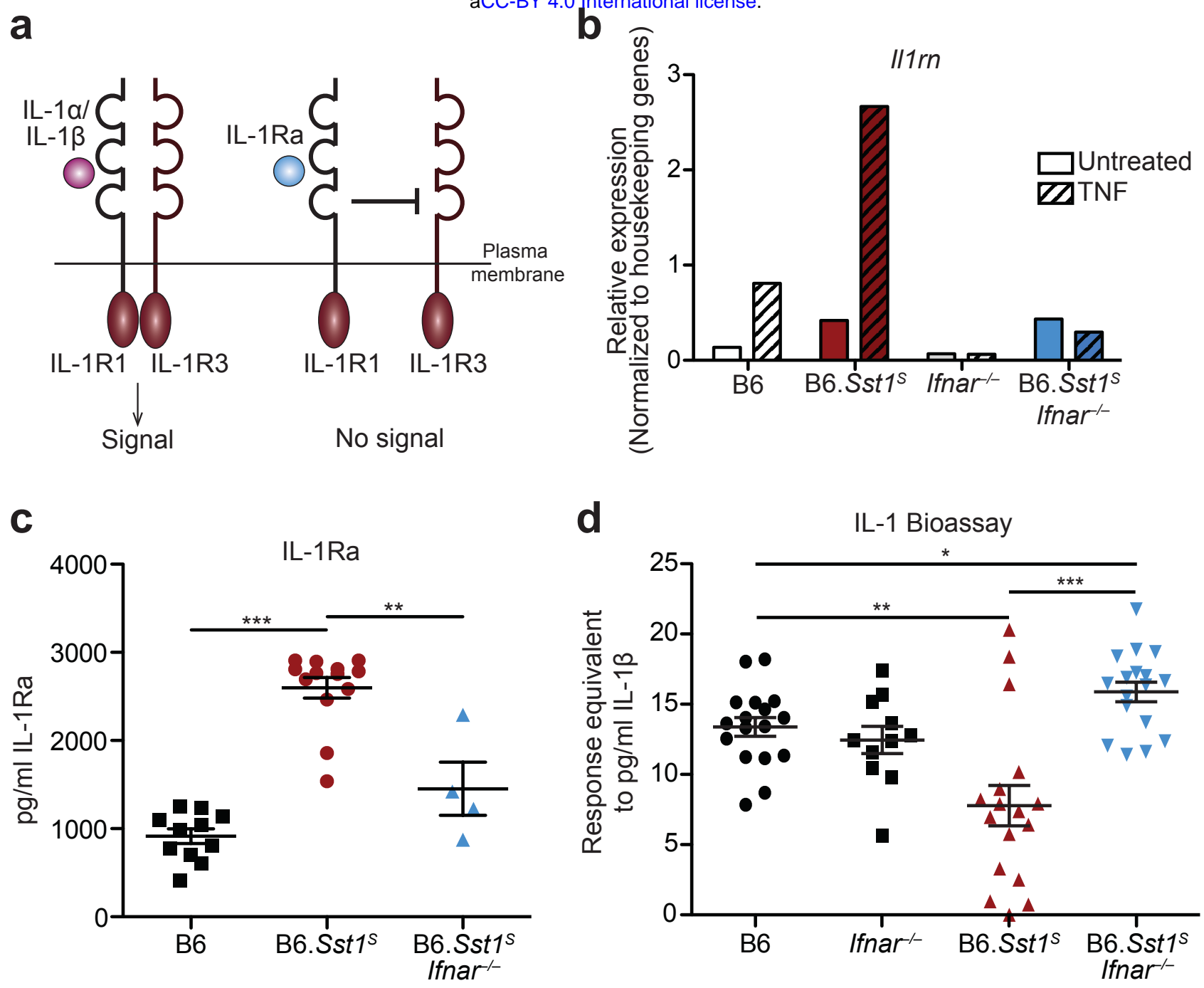

Fig. 3 | Elevated IL-1Ra and decreased functional IL-1 signaling in Mtb-infected B6.Sst1s mice. a, Schematic of IL-1R signaling. $\mathbf{b}, / 11 \mathrm{rn}$ expression in BMMs treated with $10 \mathrm{ng} / \mathrm{ml}$ TNFa for 24 hours. c, IL-1Ra protein levels and d, IL-1 reporter assay measuring functional IL-1 activity in lungs of Mtb-infected mice at day 25. Combined results of three independent infections (d) or representative of at least two independent experiments (b, c). All animals except B6 were bred in-house (a-c). Error bars are SEM. Analyzed with two-ended Mann-Whitney test (c, d). Asterisk, $p$ $\leq 0.05$; two asterisks, $p \leq 0.01$; three asterisks, $p \leq 0.001$. 
150 generated both heterozygous B6.Sst1 $\mathrm{Illrn}^{+/-}$and homozygous B6.Sst1 $1 \mathrm{Il1} \mathrm{rn}^{-1-}$ mice.

151 Both heterozygous and homozygous Illrn deficiency protected B6.Sst ${ }^{S}$ mice from Mtb.

152 In fact, bacterial burdens in B6.Sst ${ }^{S} I l 1 r^{-1-}$ mice were even lower than those found in

153 'resistant' B6 mice (Fig. 4a). Notably, a partial reduction in IL-1Ra levels due to

154 heterozygous deficiency of Illrn was sufficient to almost entirely reverse the enhanced

155 IFN-driven susceptibility of $S_{s t} 1^{S}$ mice (Fig. 4b). Histological samples of infected lungs

156 showed significant reduction in lesion sizes in both B6.Sst ${ }^{S} \mathrm{IlIrn}^{+/-}$and B6.Sst ${ }^{S} \mathrm{IlIrn}^{-/}$

157 mice as compared to B6.Sst ${ }^{S}$ (Fig. 4c). Despite concerns that enhanced IL-1 signaling

158 may cause immunopathology, both B6.Sst ${ }^{S} I l 1 \mathrm{rn}^{+-}$and B6.Sst ${ }^{S} I l 1 \mathrm{Rn}^{-/-}$mice retained

159 more body weight and exhibited increased survival as compared to infected B6.Sst $1^{S}$ mice

160 (Fig. 4b, Fig.S5a).

161 The dramatic protective effects of even partial reductions in IL-1Ra suggested

162 that IL-1Ra might be a suitable target for host-directed therapy during Mtb infection. To

163 test this idea, we treated infected B6.Sst $1^{S}$ mice with an anti-IL-1Ra antibody ${ }^{57}$ to block

164 IL-1Ra and restore IL-1 signaling (Fig. 4d). B6.Sst $1^{S}$ mice that received the antibody for

165 two weeks had significantly lower bacterial burdens in their lungs as compared to those

166 receiving a control injection of PBS. In addition, mice treated with anti-IL-1Ra antibody

167 retained significantly more body weight than their control counterparts (Fig. 4e), and

168 exhibited reduced lung lesions (Fig. 4f), suggesting that the treatment did not cause

169 detrimental inflammation. Overall these data indicate that genetic or antibody-mediated

170 reduction of IL-1Ra rescues the type I IFN-driven susceptibility in B6.Sst $1^{S}$ mice without

171 overt detrimental immunopathology.

\section{Discussion}

174 There is increasing interest in developing host-directed therapeutics for $M t b^{14}$. Although

175 such therapeutics have not yet proven to be curative, and may thus be unlikely to replace

176 antibiotics, host-directed therapies may offer some advantages in specific scenarios. For

177 example, host-directed therapy could serve as an adjunct to antibiotic regimens in

178 multidrug-resistant or extensively-drug resistant tuberculosis, where mortality is at

$17920 \%{ }^{58,59}$. It may also be more difficult for $M t b$ strains to evolve resistance to a host-

180 directed therapy, an important consideration given the increasing prevalence of multi-

181 drug resistant $M t b$ strains. In addition, our results, along with those of others ${ }^{3,4}$, suggest a 
bioRxiv preprint doi: https://doi.org/10.1101/389288; this version posted August 10,2018 . The copyright holder for this preprint (which was not certified by peer review) is the author/funder, who has granted bioRxiv a license to display the preprint in perpetuity. It is made available under

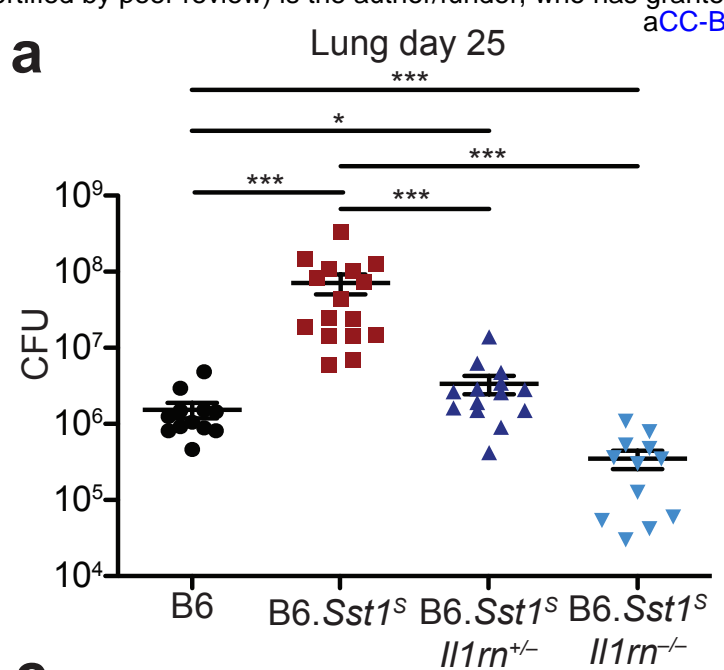
CC-BY 4.0 International license.

C
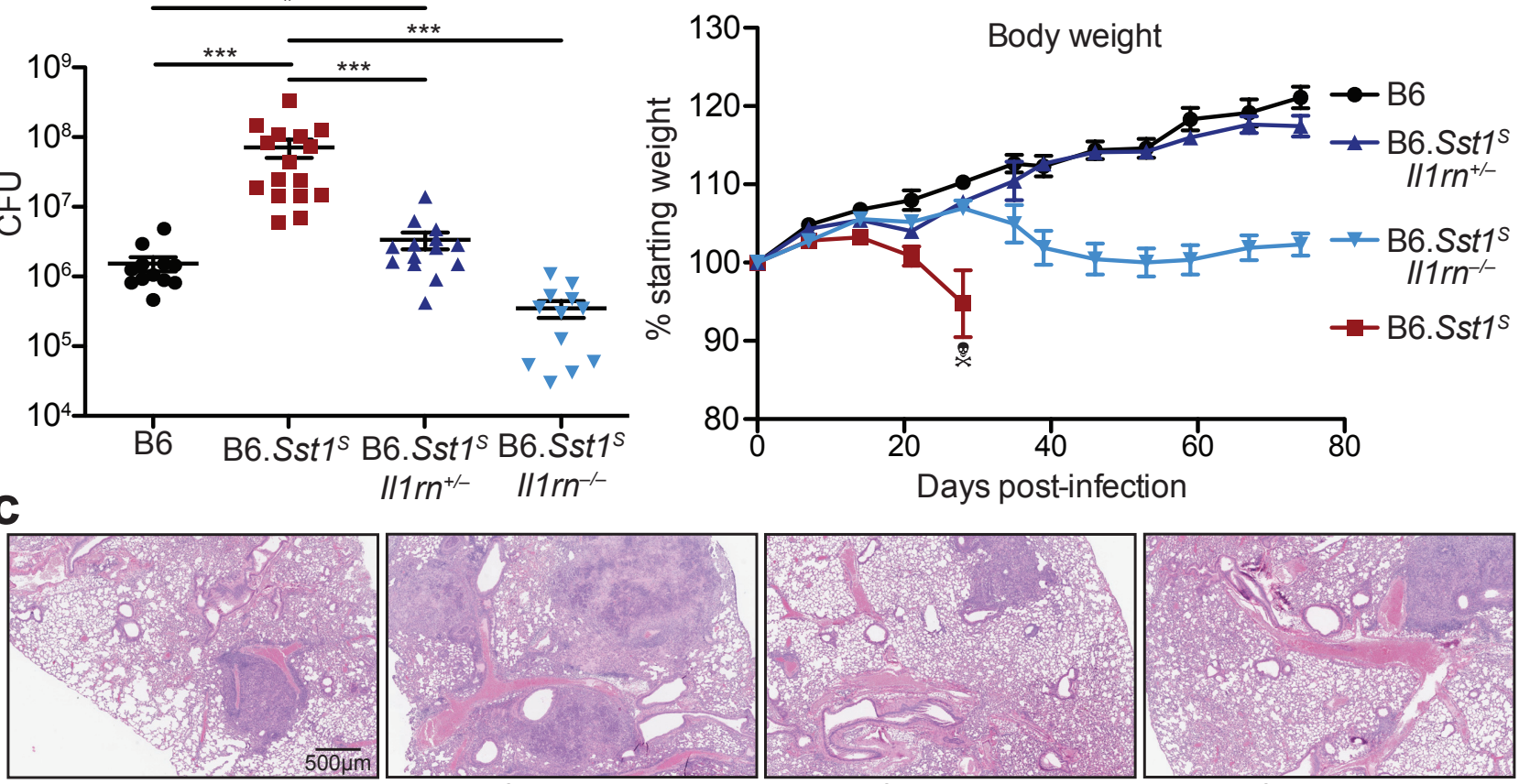

d

B6.Sst1 ${ }^{S}$

B6.Sst1 $1^{\mathrm{S}} / 1 \mathrm{rn}^{+/}$

B6.Sst1 ${ }^{S} / 11 \mathrm{rn}^{-/-}$

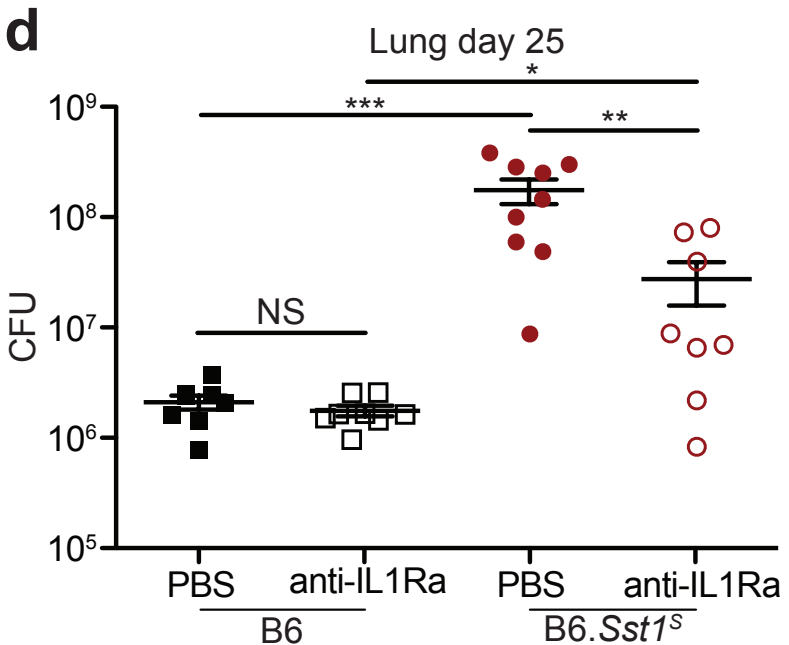

e
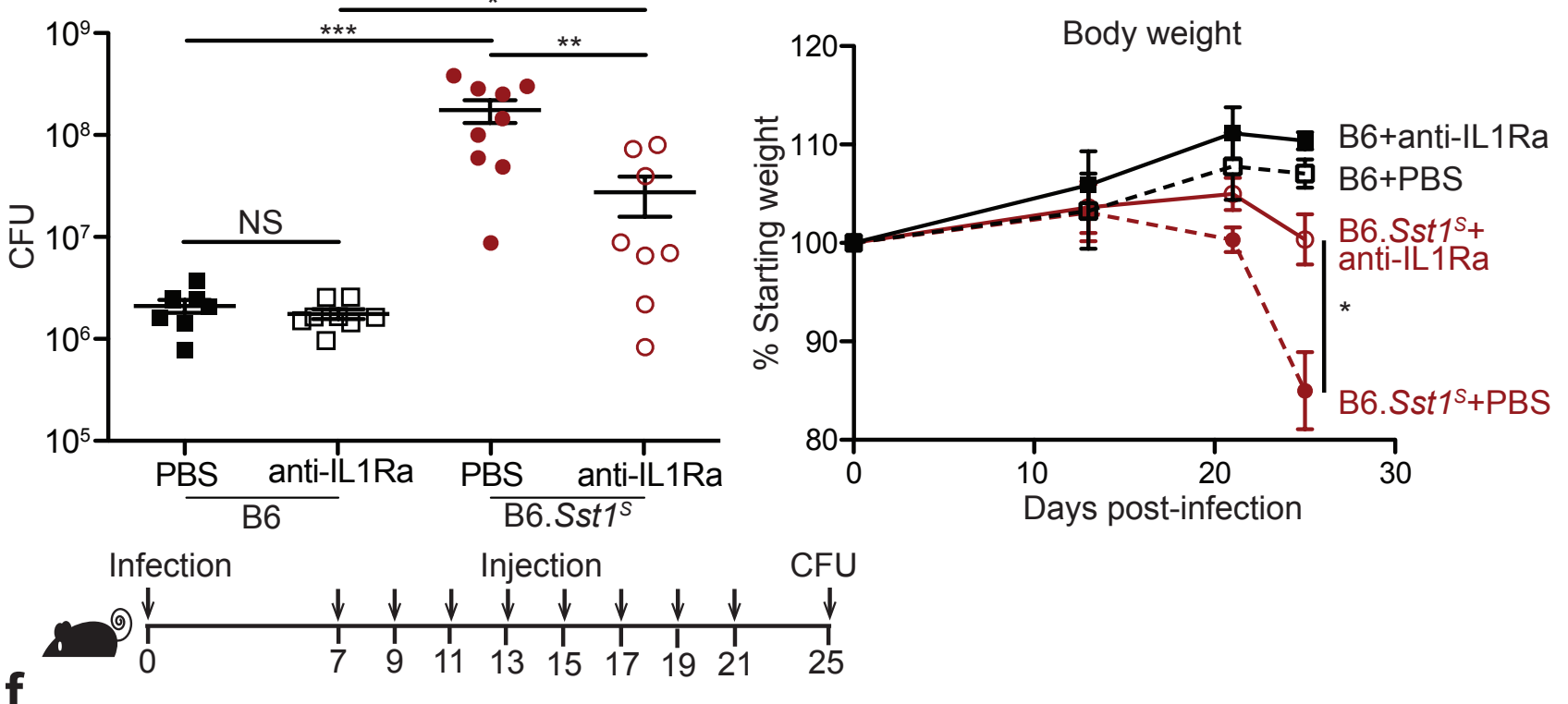

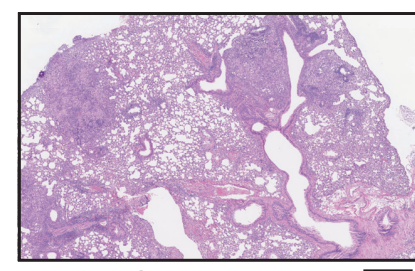

B6+PBS

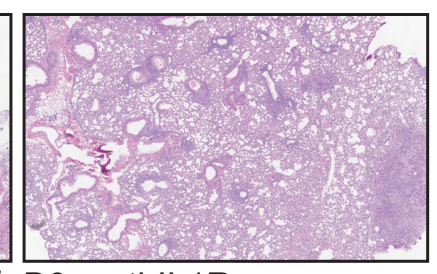

$5 \overline{00 \mu m}$ B6+anti-IL1Ra

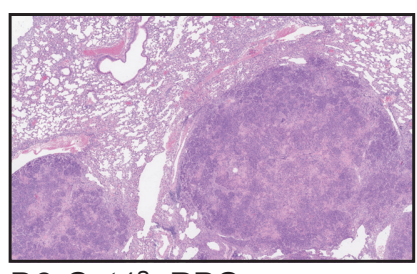

B6.Sst1 $1^{\mathrm{S}}+\mathrm{PBS}$

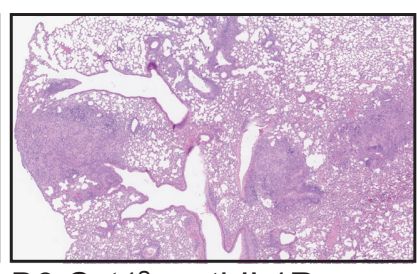

B6.Sst1 ${ }^{\text {S }}+$ anti-IL1Ra

Fig. 4 | Inhibition of IL-1Ra rescues the susceptibility of B6.Sst1s mice. a-c, Lungs of Mtb-infected mice at day 25 were measured for (a) bacterial burdens in the lungs, (b) body weight, or (c) lung sections were stained with hematoxylin and eosin (H\&E) for histology. d-f, Mtb-infected mice were treated with anti-IL1Ra antibody or PBS and (d) lung bacterial burdens were measured at day 25, or (f) day 25 lung sections were stained with $\mathrm{H} \& \mathrm{E}$, or (e) body weights were recorded over time. All were bred in-house, and all except B6 and B6.Sst $1^{\text {S }}$ were littermates (a-c); B6.Sst ${ }^{S}$ were bred in-house (d-f). Error bars are SEM. Analyzed with two-ended Mann-Whitney test (a, b, d, e). Asterisk, $p \leq 0.05$; two asterisks, $p \leq 0.01$; three asterisks, $p \leq 0.001$. 
182 strategy in which latently infected individuals could be screened for the type I IFN

183 signature known to be a strong predictor of progression to active TB. If the type I IFN

184 signature in these individuals could then be reset or reversed by a host-directed therapy

185 targeting IL-1Ra, or other host factors ${ }^{22}$, then it might be possible to prevent progression

186 to active TB - the transmissible form of the disease — without the prolonged (6-month)

187 antibiotic treatments that are associated with poor compliance and emergence of drug-

188 resistant strains. This therapeutic strategy, though only presented here as a proof-of-

189 concept in animals, may help focus treatments on those who are likely to transmit among

190 the billions of latently infected persons. The success of such a strategy would not

191 necessarily require microbiological cure, but would depend on identification of highly

192 potent master-regulators of interferon-driven TB disease that can be readily targeted

193 clinically in TB endemic areas. Identification of such regulators and development of

194 therapies appropriate for resource-limited settings will require better animal models of

195 interferon-driven TB disease in vivo. Our results show that the B6.Sst $1^{S}$ mouse may

196 represent a useful model of IFN-driven TB disease in humans and suggest that

197 therapeutic targeting of IL-1Ra may be a potent strategy for reversing type I IFN-driven

198 susceptibility in vivo.

\section{References}

201 1. World Health Organization. Global Tuberculosis Report 2017. Geneva; 2017.

202 2. Houben RM, Dodd PJ. The Global Burden of Latent Tuberculosis Infection: A Re-

203 estimation Using Mathematical Modelling. PLoS Med. 2016;13(10): e1002152.

204 doi:10.1371/journal.pmed.1002152.

205 3. Zak DE, Penn-Nicholson A, Scriba TJ, et al. A blood RNA signature for tuberculosis disease risk: a prospective cohort study. Lancet. 2016;387(10035):2312-2322. doi:10.1016/S0140-6736(15)01316-1.

4. Scriba TJ, Penn-Nicholson A, Shankar S, et al. Sequential inflammatory processes define human progression from $M$. tuberculosis infection to tuberculosis disease. PLoS Pathog. 2017;13(11):e1006687. doi:10.1371/journal.ppat.1006687.

5. Berry MP, Graham CM, Mcnab FW, et al. An interferon-inducible neutrophildriven blood transcriptional signature in human tuberculosis. Nature. 2010;466(7309):973-977. doi:10.1542/peds.2011-2107LLLL.

6. Moreira-Teixeira L, Mayer-Barber K, Sher A, O'Garra A. Type I interferons in tuberculosis: Foe and occasionally friend. J Exp Med. 2018;215(5):1273-1285. doi:10.1084/jem.20180325.

7. Donovan ML, Schultz TE, Duke TJ, Blumenthal A. Type I Interferons in the Pathogenesis of Tuberculosis: Molecular Drivers and Immunological Consequences. Front Immunol. 2017;8(Nov):1633. 
doi:10.3389/fimmu.2017.01633.

8. Singhania A, Verma R, Graham CM, et al. A modular transcriptional signature identifies phenotypic heterogeneity of human tuberculosis infection. Nat Commun. 2018;9(2308). doi:10.1101/216879.

9. Pan H, Yan B-S, Rojas M, et al. Ipr1 gene mediates innate immunity to tuberculosis. Nature. 2005;434(7034):767-772. doi:10.1038/nature03419.

10. Pichugin AV, Yan BS, Sloutsky A, Kobzik L, Kramnik I. Dominant role of the sst1 locus in pathogenesis of necrotizing lung granulomas during chronic tuberculosis infection and reactivation in genetically resistant hosts. Am J Pathol. 2009;174(6):2190-2201. doi:10.2353/ajpath.2009.081075.

11. McNab F, Mayer-Barber K, Sher A, Wack A, O'Garra A. Type I interferons in infectious disease. Nat Rev Immunol. 2015;15(2):87-103. doi:10.1038/nri3787.

12. Boxx GM, Cheng G. The Roles of Type I Interferon in Bacterial Infection. Cell Host Microbe. 2016;19(6):760-769. doi:10.1016/j.chom.2016.05.016.

13. Nunes-Alves C, Booty MG, Carpenter SM, Jayaraman P, Rothchild AC, Behar SM. In search of a new paradigm for protective immunity to TB. Nat Rev Microbiol. 2014;12(4):289-299. doi:10.1038/nrmicro3230.

14. Hawn TR, Shah JA, Kalman D. New tricks for old dogs: Countering antibiotic resistance in tuberculosis with host-directed therapeutics. Immunol Rev. 2015;264(1):344-362. doi:10.1111/imr.12255.

15. Zhang G, deWeerd NA, Stifter SA, et al. A proline deletion in IFNAR1 impairs IFN-signaling and underlies increased resistance to tuberculosis in humans. Nat Commun. 2018;9(1):85. doi:10.1038/s41467-017-02611-z.

16. Manca C, Tsenova L, Freeman S, et al. Hypervirulent M. tuberculosis W/Beijing Strains Upregulate Type I IFNs and Increase Expression of Negative Regulators of the Jak-Stat Pathway. J Interf Cytokine Res. 2005;25(11):694-701. doi:10.1089/jir.2005.25.694.

17. Teles RMB, Graeber TG, Krutzik SR, et al. Type I Interferon Suppresses Type II Interferon-Triggered Human Anti-Mycobacterial Responses. Science (80- ). 2013;339(6126):1448-1453. doi:10.1126/science.1233665.

18. Stanley SA, Johndrow JE, Manzanillo P, Cox JS. The Type I IFN response to infection with Mycobacterium tuberculosis requires ESX-1-mediated secretion and contributes to pathogenesis. J Immunol. 2007;178(5):3143-3152. doi:10.4049/jimmunol.178.5.3143.

19. Desvignes L, Wolf AJ, Ernst JD. Dynamic Roles of Type I and Type II IFNs in Early Infection with Mycobacterium tuberculosis. J Immunol. 2012;188(12):62056215. doi:10.4049/jimmunol.1200255.

20. Moreira-Teixeira L, Sousa J, McNab FW, et al. Type I IFN Inhibits Alternative Macrophage Activation during Mycobacterium tuberculosis Infection and Leads to Enhanced Protection in the Absence of IFN- $\gamma$ Signaling. J Immunol. 2016;197(12):4714-4726. doi:10.4049/jimmunol.1600584.

21. Antonelli LR, Rothfuchs AG, Gonçalves R, et al. Intranasal poly-IC treatment exacerbates tuberculosis in mice through the pulmonary recruitment of a pathogenpermissive monocyte/macrophage population. J Clin Invest. 2010;120(5):16741682. doi:10.1172/JCI40817.

22. Mayer-Barber KD, Andrade BB, Oland SD, et al. Host-directed therapy of 
tuberculosis based on interleukin-1 and type I interferon crosstalk. Nature. 2014;511 VN-(7507):99-103. doi:10.1038/nature13489.

23. Dorhoi A, Yeremeev V, Nouailles G, et al. Type I IFN signaling triggers immunopathology in tuberculosis-susceptible mice by modulating lung phagocyte dynamics. Eur J Immunol. 2014;44(8):2380-2393. doi:10.1002/eji.201344219.

24. Bhattacharya $B$, Chatterjee $S$, Berland $R$, et al. Increased susceptibility to intracellular bacteria and necrotic inflammation driven by a dysregulated macrophage response to TNF. bioRxiv. 2018. http://biorxiv.org/content/early/2018/03/15/238873.abstract.

25. He X, Berland R, Mekasha S, et al. The sst1 Resistance Locus Regulates Evasion of Type I Interferon Signaling by Chlamydia pneumoniae as a Disease Tolerance Mechanism. PLoS Pathog. 2013;9(8). doi:10.1371/journal.ppat.1003569.

26. Dunn GP, Bruce AT, Sheehan KC, et al. A critical function for type I interferons in cancer immunoediting. Nat Immunol. 2005;6(7):722-729. doi:10.1038/ni1213.

27. Watson RO, Bell SL, MacDuff DA, et al. The Cytosolic Sensor cGAS Detects Mycobacterium tuberculosis DNA to Induce Type I Interferons and Activate Autophagy. Cell Host Microbe. 2014;17(6):811-819. doi:10.1016/j.chom.2015.05.004.

28. Wassermann R, Gulen MF, Sala C, et al. Mycobacterium tuberculosis Differentially Activates cGAS- and Inflammasome-Dependent Intracellular Immune Responses through ESX-1. Cell Host Microbe. 2015;17(6):799-810. doi:10.1016/j.chom.2015.05.003.

29. Wiens KE, Ernst JD. The Mechanism for Type I Interferon Induction by Mycobacterium tuberculosis is Bacterial Strain-Dependent. PLoS Pathog. 2016;12(8):1-20. doi:10.1371/journal.ppat.1005809.

30. Collins AC, Cai H, Li T, et al. Cyclic GMP-AMP Synthase Is an Innate Immune DNA Sensor for Mycobacterium tuberculosis. Cell Host Microbe. 2015;17(6):820828. doi:10.1016/j.chom.2015.05.005.

31. Dey B, Dey RJ, Cheung LS, et al. A bacterial cyclic dinucleotide activates the cytosolic surveillance pathway and mediates innate resistance to tuberculosis. Nat Med. 2015;21(4):401-408. doi:10.1038/nm.3813.

32. McNab FW, Ewbank J, Howes A, et al. Type I IFN induces IL-10 production in an IL-27-independent manner and blocks responsiveness to IFN- $\gamma$ for production of IL-12 and bacterial killing in Mycobacterium tuberculosis-infected macrophages. $J$ Immunol. 2014;193(7):3600-3612. doi:10.4049/jimmunol.1401088.

33. Eshleman EM, Delgado C, Kearney SJ, Friedman RS, Lenz LL. Down regulation of macrophage IFNGR1 exacerbates systemic L. monocytogenes infection. PLoS Pathog. 2017;13(5):1-22. doi:10.1371/journal.ppat.1006388.

34. Reboldi A, Dang EV., McDonald JG, Liang G, Russell DW, Cyster JG. 25Hydroxycholesterol suppresses interleukin-1 driven inflammation downstream of type 1 interferon. Science (80- ). 2014;345(6197):679-684. doi:10.1126/science. 1254790 .

35. Novikov A, Cardone M, Thompson R, et al. Mycobacterium tuberculosis Triggers Host Type I IFN Signaling To Regulate IL-1 Production in Human Macrophages. J Immunol. 2011;187(5):2540-2547. doi:10.4049/jimmunol.1100926.

311 36. Mayer-Barber KD, Andrade BB, Barber DL, et al. Innate and Adaptive Interferons 
Suppress IL- $1 \alpha$ and IL-1 $\beta$ Production by Distinct Pulmonary Myeloid Subsets during Mycobacterium tuberculosis Infection. Immunity. 2011;35(6):1023-1034. doi:10.1016/j.immuni.2011.12.002.

37. Mayer-Barber KD, Yan B. Clash of the Cytokine Titans: counter-regulation of interleukin-1 and type I interferon-mediated inflammatory responses. Cell Mol Immunol. 2016;14(April):1-14. doi:10.1038/cmi.2016.25.

38. Mishra BB, Rathinam VAK, Martens GW, et al. Nitric oxide controls the immunopathology of tuberculosis by inhibiting NLRP3 inflammasome-dependent processing of IL-1ß. Nat Immunol. 2013;14(1):52-60. doi:10.1038/ni.2474.

39. Mishra BB, Lovewell RR, Olive AJ, et al. Nitric oxide prevents a pathogenpermissive granulocytic inflammation during tuberculosis. Nat Microbiol. 2017;2(May):17072. doi:10.1038/nmicrobiol.2017.72.

40. Nichols RD, Von Moltke J, Vance RE. NAIP/NLRC4 inflammasome activation in MRP8+ cells is sufficient to cause systemic inflammatory disease. Nat Commun. 2017;8(1). doi:10.1038/s41467-017-02266-w.

41. Fremond CM, Togbe D, Doz E, et al. IL-1 Receptor-Mediated Signal Is an Essential Component of MyD88-Dependent Innate Response to Mycobacterium tuberculosis Infection. J Immunol. 2007;179(2):1178-1189. doi:10.4049/jimmunol.179.2.1178.

42. Mayer-Barber KD, Barber DL, Shenderov K, et al. Caspase-1 Independent IL-1 Production Is Critical for Host Resistance to Mycobacterium tuberculosis and Does Not Require TLR Signaling In Vivo. J Immunol. 2010;184(7):3326-3330. doi:10.4049/jimmunol.0904189.

43. Yamada H, Mizumo S, Horai R, Iwakura Y, Sugawara I. Protective role of interleukin-1 in mycobacterial infection in IL-1 alpha/beta double-knockout mice. Lab Investig. 2000;80(5):759-767.

44. Sugawara I, Yamada H, Hua S, Mizuno S. Role of interleukin (IL)-1 type 1 receptor in mycobacterial infection. Microbiol Immunol. 2001;45(11):743-750.

45. Di Paolo NC, Shafiani S, Day T, et al. Interdependence between Interleukin-1 and Tumor Necrosis Factor Regulates TNF-Dependent Control of Mycobacterium tuberculosis Infection. Immunity. 2015;43(6):1125-1136. doi:10.1016/j.immuni.2015.11.016.

46. Juffermans NP, Florquin S, Camoglio L, et al. Interleukin-1 signaling is essential for host defense during murine pulmonary tuberculosis. J Infect Dis. 2000;182(3):902-908. doi:10.1086/315771.

47. Eisenberg S, Evans R, Arend W, et al. Primary structure and functional expression from complementary DNA of a human interleukin-1 receptor antagonist. Nature. 1990;343(6256):341-346. doi:10.1038/343341a0.

48. Dinarello CA. Overview of the IL-1 family in innate inflammation and acquired immunity. Immunol Rev. 2018;281(1):8-27. doi:10.1111/imr.12621.

49. Molnarfi N, Hyka-Nouspikel N, Gruaz L, Dayer J-M, Burger D. The production of IL-1 receptor antagonist in IFN-beta-stimulated human monocytes depends on the activation of phosphatidylinositol 3-kinase but not of STAT1. J Immunol. 2005;174(5):2974-2980. doi:10.4049/jimmunol.174.5.2974.

50. Corr M, Boyle DL, Ronacher LM, et al. Interleukin 1 receptor antagonist mediates the beneficial effects of systemic interferon beta in mice: implications for 
rheumatoid arthritis. Ann Rheum Dis. 2011;70(5):858-863. doi:10.1136/ard.2010.141077.

51. Janssen S, Schutz C, Ward A, et al. Mortality in Severe Human Immunodeficiency Virus-Tuberculosis Associates With Innate Immune Activation and Dysfunction of Monocytes. Clin Infect Dis. 2017;65(1):73-82. doi:10.1093/cid/cix254.

52. Settas LD, Tsimirikas G, Vosvotekas G, Triantafyllidou E, Nicolaides P.

Reactivation of pulmonary tuberculosis in a patient with rheumatoid arthritis during treatment with IL-1 receptor antagonists (anakinra). J Clin Rheumatol. 2007;13(4):219-220. doi:10.1097/RHU.0b013e31812e00a1.

53. He D, Bai F, Zhang S, et al. High incidence of tuberculosis infection in rheumatic diseases and impact for chemoprophylactic prevention of tuberculosis activation during biologics therapy. Clin vaccine Immunol. 2013;20(6):842-847. doi:10.1128/CVI.00049-13.

54. Brassard P, Kezouh A, Suissa S. Antirheumatic drugs and the risk of tuberculosis. Clin Infect Dis. 2006;43(6):717-722. doi:http://dx.doi.org/10.1086/506935.

55. Hirsch E, Irikura VM, Paul SM, Hirsh D. Functions of interleukin 1 receptor antagonist in gene knockout and overproducing mice. Proc Natl Acad Sci U S A. 1996;93(20):11008-11013. doi:10.1073/pnas.93.20.11008.

56. Dinarello CA. Immunological and inflammatory functions of the interleukin-1 family. Annu Rev Immunol. 2009;27:519-550. doi:10.1146/annurev.immunol.021908.132612.

57. Fujioka N, Mukaida N, Harada A, et al. Preparation of specific antibodies against murine IL-1ra and the establishment of IL-1ra as an endogenous regulator of bacteria-induced fulminant hepatitis in mice. J Leukoc Biol. 1995;58(1):90-98.

58. Mitnick CD, Franke MF, Rich ML, et al. Aggressive regimens for multidrugresistant tuberculosis decrease all-cause mortality. PLoS One. 2013;8(3):e58664. doi:10.1371/journal.pone.0058664.

59. Chung-Delgado K, Guillen-Bravo S, Revilla-Montag A, Bernabe-Ortiz A. Mortality among MDR-TB cases: comparison with drug-susceptible tuberculosis and associated factors. PLoS One. 2015;10(3):e0119332. doi:10.1371/journal.pone.0119332.

\section{Acknowledgements}

391 We thank the Stanley and Cox labs for discussions and for support with Mtb and BSL3

392 experiments. We thank the Barton lab for discussions, L. Flores, P. Dietzen and R.

393 Chavez for technical assistance, H. Nolla and A. Valeros and the Cancer Research

394 Laboratory for flow cytometry. We thank A. Sandstrom, I. Rauch and P. Mitchell for

395 helpful discussions and technical support. We thank J. Price, L. DiPeso and R. Merl for

396 support with the RNAseq. We thank B. Penn for comments on the manuscript.

397 Generation of the anti-IL1RA antibody was supported by the Extramural Collaborative

398 Research Program of Cancer Research Institute, Kanazawa University. K.H.D and R.E.V.

399 were supported by Investigator in the Pathogenesis of Infectious Diseases awards from 
400 the Burroughs Wellcome Fund. R.E.V. is an HHMI Investigator and is supported by NIH

401 grants AI075039 and AI066302.

402

403 Methods

404 Mice. All mice were specific pathogen-free, maintained under a 12-hr light-dark cycle

405 (7AM to 7PM), and given a standard chow diet (Harlan irradiated laboratory animal diet)

406 ad libitum. All mice were sex and age-matched at 6-8 weeks old at the beginning of

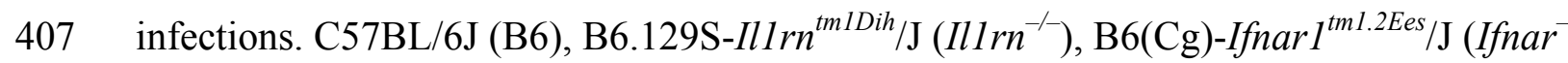

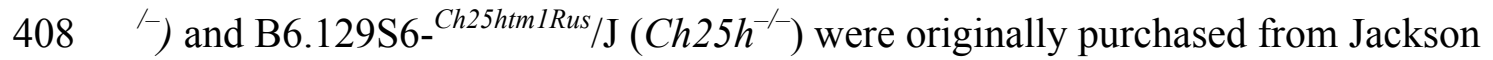

409 Laboratories and subsequently bred at UC Berkeley. B6J.C3-Sst ${ }^{\mathrm{C} 3 \mathrm{HeB} / \mathrm{FeJKrmn}}$ mice

410 (referred to as B6.Sst ${ }^{S}$ throughout) were from the colony of I. Kramnik at Boston

411 University and then transferred to UC Berkeley. Sting ${ }^{g t / g t}$ mice were previously

412 described ${ }^{1}$. All animals used in experiments were bred in-house unless otherwise noted in

413 the figure legends. All animal experiments complied with the regulatory standards of, and

414 were approved by, the University of California Berkeley Institutional Animal Care and

415 Use Committee.

416 Mycobacterium tuberculosis infections. Mtb strain Erdman (gift of S.A. Stanley) was

417 used for all infections. Frozen stocks of this wild-type strain were made from a single

418 culture and used for all experiments. Cultures for infection were grown in Middlebrook

4197 H9 liquid medium supplemented with 10\% albumin-dextrose-saline, $0.4 \%$ glycerol and

$420 \quad 0.05 \%$ Tween- 80 for five days at $37^{\circ} \mathrm{C}$. Mice were aerosol infected using an inhalation

421 exposure system (Glas-Col, Terre Haute, IN). A total of $9 \mathrm{ml}$ of culture was loaded into

422 the nebulizer calibrated to deliver $\sim 20$ to 50 bacteria per mouse as measured by colony

423 forming units (CFUs) in the lungs 1 day following infection (data not shown). Mice were

424 sacrificed at 14 days or 25 days post-infection to measure CFUs and/or cytokines. All but

4251 lung lobe was homogenized in PBS plus $0.05 \%$ Tween-80 or processed for cytokines

426 (see below), and serial dilutions were plated on 7H11 plates supplemented with 10\%

427 oleic acid, albumin, dextrose, catalase (OADC) and $0.5 \%$ glycerol. CFUs were counted

42821 days after plating. The remaining lobe was used for histology or for RNA extraction.

429 For histology the sample was fixed in $10 \%$ formalin for at least 48 hours then stored in

$43070 \%$ ethanol. Samples were sent to Histowiz Inc for embedding in wax, sectioning and 431 staining. 
432 Cytokine measurements. Cell-free lung homogenates were generated as previously

433 described ${ }^{2}$. Briefly, lungs were crushed through $100 \mu \mathrm{m}$ Falcon cell strainers in sterile

434 PBS with 1\% FBS and Pierce Protease Inhibitor (Thermo Fisher). An aliquot was

435 removed for measuring CFU by plating as described above. Cells and debris were then

436 removed by low-speed centrifugation $(300 \times g)$ and the resulting cell-free homogenate was

437 filtered twice with $0.2 \mu \mathrm{m}$ filters to remove all $M t b$ for work outside of BSL3. All

438 homogenates were aliquoted, flash-frozen in liquid nitrogen and stored at $-80^{\circ} \mathrm{C}$. Each

439 aliquot was thawed a maximum of twice to avoid potential artifacts due to repeated

440 freeze-thaw cycles. All cytokines except IL-10 and IL-1Ra was measured using

441 Cytometric Bead Assay (BD Biosciences) according to manufacturer protocols. Results

442 were collected using BD LSRFortessa (BD Biosciences) and analyzed using FCAP Array

443 v3.0. IL-10 levels were measured using Mouse IL-10 ELISA Ready-SET-Go! $\left(2^{\text {nd }}\right.$

444 Generation, eBioscience). IL-1Ra levels were measured by ELISA using Mouse IL-

445 1ra/IL-1F3 Quantikine ELISA Kit (R\&D Systems) according to manufacturer protocols.

446 IL-1 bioactivity reporter assay. Mice were infected with $\sim 25-35$ bacteria per mouse and

447 sacrificed at 25 days-post infection to prepare cell-free lung homogenates. Assays were

448 performed using HEK-Blue ${ }^{\mathrm{TM}}$ IL-1R cells (InvivoGen) with minor modifications. Cells

449 were cultured under antibiotic-selection according to manufacturer protocols. Cells were

450 plated at $5 \times 10^{4}$ cells/well in $50 \mu 1$ in 96 -well plates, and allowed to adhere overnight in

451 DMEM supplemented with 10\% FBS, 2mM glutamine, $100 \mathrm{U} / \mathrm{ml}$ streptomycin and 100

$452 \mu \mathrm{g} / \mathrm{ml}$ penicillin in a humidified incubator $\left(37^{\circ} \mathrm{C}, 5 \% \mathrm{CO}_{2}\right) .50 \mu$ l cell-free lung

453 homogenates or standard curve made from recombinant mouse IL-1 $\beta$ (R\&D systems 401-

454 ML-005) were added to the cells and incubated overnight in a humidified incubator.

455 Assays were developed using QUANTI-Blue (InvivoGen) according to manufacturer

456 protocols. Experiments in which the initial CFU was either too high or too low produced

457 inconsistent results in this assay.

458 Flow cytometry. Lungs were perfused with $10 \mathrm{ml}$ of cold PBS and strained through

$45940 \mu \mathrm{m}$ cell strainers. Aliquots were removed for quantifying CFU. Cells were washed and

460 stained with fixable viability dye (Thermo Fisher 65-0865-14). An aliquot of cells from

461 each sample were removed and mixed with counting beads (Thermo Fisher C36950) for

462 later enumeration. The rest of the cells were incubated with anti-mouse CD16/CD32

463 monoclonal antibody to block Fc receptors (Thermo Fisher 14-0161-81), then with 
464 antibodies for surface staining. The following antigens were stained for: CD45 (30-F11,

465 Biolegend 103107), CD11b (M1/70, Thermo Fisher 48-0112-82), CD11c (N418,

466 Biolegend 117335), Ly6G (1A8, BD Biosciences 740554), Ly6C (HK1.4, Thermo Fisher

467 17-5932-80), CD24 (M1/69, BD Bioscience 564664), MHC II (M5/114.15.2, Biolegend

468 107625), SiglecF (E50-2440, BD Biosciences 562680). Cells were fixed with fixation

469 buffer (BD Biosciences 554714) for at least 1 hour at room temperature and stored in

470 PBS with $1 \%$ FBS and $2 \mathrm{mM}$ EDTA overnight at $4{ }^{\circ} \mathrm{C}$ in the dark. Data were acquired on

471 a BD Fortessa X-20 flow cytometer and analyzed with FlowJo v10.

472 Bone marrow-derived macrophages (BMMs) and TNF-treatment. Bone marrow was

473 harvested from mouse femurs and tibias, and cells were differentiated by culture on non-

474 tissue culture-treated plates in RPMI supplemented with supernatant from 3T3-MCSF

475 cells (gift of B. Beutler), 10\% fetal bovine serum (FBS), 2mM glutamine, $100 \mathrm{U} / \mathrm{ml}$

476 streptomycin and $100 \mu \mathrm{g} / \mathrm{ml}$ penicillin in a humidified incubator $\left(37^{\circ} \mathrm{C}, 5 \% \mathrm{CO}_{2}\right)$. $\mathrm{BMMs}$

477 were harvested six days after plating and frozen in 95\% FBS and 5\% DMSO. For in vitro

478 experiments, BMMs were thawed into media as described above for 4 hours in a

479 humidified $37^{\circ} \mathrm{C}$ incubator. Adherent cells were washed with PBS, counted and replated

480 at $1.2 \times 10^{6} \sim 1.5 \times 10^{6}$ cells/well in a TC-treated 6-well plate. Cells were treated with 10

$481 \mathrm{ng} / \mathrm{ml}$ recombinant mouse TNF $\alpha$ (410-TRNC-010, R\&D systems) diluted in the media as

482 described above.

483 Quantitative RT-PCR. Total RNA from BMMs was extract using RNeasy total RNA kit

484 (Qiagen) according to manufacturer specifications. Total RNA from infected tissues was

485 extracted by homogenizing in TRIzol reagent (Life technologies) then mixing thoroughly

486 with chloroform, both done under BSL3 conditions. Samples were then removed from the

487 BSL3 facility and transferred to fresh tubes under BSL2 conditions. Aqueous phase was

488 separated by centrifugation and RNA was further purified using an RNeasy total RNA kit

489 (Qiagen). Equal amounts of RNA from each sample were treated with DNase (RQ1,

490 Promega) and cDNA was made using Superscript III (Invitrogen). Complementary

491 cDNA reactions were primed with poly $(\mathrm{dT})$ for the measurement of mature transcripts.

492 For experiments with multiple time points, samples were frozen in the RLT buffer

493 (Qiagen) or RNAlater ${ }^{\mathrm{TM}}$ solution (Invitrogen). Quantitative PCR was performed using

494 QuantiStudio 5 Real-Time PCR System (Applied Biosystems) with Power Sybr Green

495 PCR Master Mix (Thermo Fisher Scientific) according manufacturer specifications. 
496 Transcript levels were normalized to housekeeping genes Rps17, Actb and Oaz1 unless

497 otherwise specified. The following primers were used in this study. Rps 17 sense:

498 CGCCATTATCCC CAGCAAG; Rps 17 antisense: TGTCGGGATCCACCTCAATG;

499 Oazl sense: GTG GTG GCC TCT ACA TCG AG; Oazl antisense: AGC AGA TGA

500 AAA CGT GGT CAG; Actb sense: CGC AGC CAC TGT CGA GTC; $A c t b$ antisense:

501 CCT TCT GAC CCA TTC CCA CC; Ifnb sense: GTCCTCAACTGCTCTCCACT; Ifnb

502 antisense: CCTGCAACCACCACTCATTC; Illrn sense:

503 CGCCCTTCTGGGAAAAGACC, Illrn antisense: CCGTGGATGCCCAAGAACAC;

504 Irfl sense: TGAGGAAGGGAAGATAGCCG; Irfl antisense:

505 TGTATGCCTATCCCAATGTCCC; Irgm1 sense: AAAACCAGAGAGCCTCACCA;

506 Irgm 1 antisense: ATGTTGGGGAGTAGTGGAGC; Gbp4 sense:

507 TGAGTACCTGGAGAATGCCCT; Gbp4 antisense: TGGCCGAATTGGATGCTTGG;

508 Gbp5 sense: TGTTCTTACTGGCCCCTGCT; Gbp5 antisense:

509 CCAATGAGGCACAAGGGTTC; Ifit3 sense: AGCCCACACCCAGCTTTT; Ifit3

510 antisense: CAGAGATTCCCGGTTGACCT; Stat1 sense:

511 CAGAAAAACGCTGGGAACAGA; Stat1 antisense: CAAGCCTGGCTGGCAC; Gbp7

512 sense: AGCAAGCCCAAGTTCACACT; Gbp7 antisense:

513 TCCGCTCTGTCAGTTCTGTG.

514 RNA sequencing and analysis. Total RNA was isolated as described above. Illumina-

515 compatible libraries were generated by the University of California, Berkeley, QB3

516 Vincent J. Coates Genomics Sequencing Laboratory. The libraries were multiplexed and

517 sequenced using one flow cell on HiSeq4000 (Illumina) as 100bp paired-end reads. The

518 data were aligned using Sleuth $^{3}$ and analyzed using Kallisto ${ }^{4}$.

519 Antibody-mediated neutralization. For all antibody treatments, the schedules are

520 indicated in the figures. All treatments were delivered by intraperitoneal injection. Mouse

521 anti-mouse IFNAR1 (MAR1-5A3) and isotype control (GIR208, mouse anti-human

522 IFNGR- $\alpha$ chain) were purchased from Leinco Technologies Inc. Each mouse was given

$523500 \mu \mathrm{g}$ per injection. Hamster anti-IL1R1 antibody (mIL1R-M147) was obtained from

524 Amgen. Isotype control was Ultra-LEAF Purified Armenian Hamster IgG Isotype

525 Antibody from Biolegend (400940). Each mouse was given $200 \mu$ g per injection.

526 Armenian hamster anti-IL1Ra antibody was produced in-house using a previously

527 published hybridoma line ${ }^{5}$. Cells were grown in Wheaton CELLine Bioreactor Flasks 
528 (Fisher Scientific) according to manufacturer instructions. Media in the cell compartment

529 used ultra-low IgG FBS (ThermoFisher 16250078) to minimize bovine IgG

530 contamination during purification. Cell-free supernatant from the cell compartment was

531 purified using protein $\mathrm{G}$ resin (GenScript). IgG was eluted using $0.1 \mathrm{M}$ acetic acid, then

$53210 \%$ of total volume of $1 \mathrm{M}$ Tris $\mathrm{pH} 8$ and $0.5 \mathrm{M} \mathrm{NaCl}$ was added to neutralize. Size

533 exclusion and buffer exchange to PBS was performed using Amicon Ultra-4 Centrifugal

534 Filter Units (EMD Millipore). The final product was filter sterilized and stored at $-80^{\circ} \mathrm{C}$.

535 For injections antibody stocks were diluted in sterile PBS and each mouse received

$536500 \mu \mathrm{g}$ per injection.

537 Statistical analysis. All survival data were analyzed with Log-rank (Mantel-Cox) Test.

538 All other data were analyzed with Mann-Whitney test unless otherwise noted. Both tests

539 were run using GraphPad Prism 5. Asterisk, $p \leq 0.05$; two asterisks, $p \leq 0.01$; three

540 asterisks, $p \leq 0.001$. All error bars are s.e.

\section{Methods References}

543 1. Sauer JD, Sotelo-Troha K, Von Moltke J, et al. The N-ethyl-N-nitrosourea-induced Goldenticket mouse mutant reveals an essential function of sting in the in vivo interferon response to Listeria monocytogenes and cyclic dinucleotides. Infect

Immun. 2011;79(2):688-694. doi:10.1128/IAI.00999-10.

2. Mayer-Barber KD, Barber DL, Shenderov K, et al. Caspase-1 Independent IL-1 Production Is Critical for Host Resistance to Mycobacterium tuberculosis and Does Not Require TLR Signaling In Vivo. J Immunol. 2010;184(7):3326-3330. doi:10.4049/jimmunol.0904189.

3. Pimentel H, Bray NL, Puente S, Melsted P, Pachter L. Differential analysis of RNA-seq incorporating quantification uncertainty. Nat Methods. 2017;14(7):687690. doi:10.1038/nmeth.4324.

4. Bray NL, Pimentel H, Melsted P, Pachter L. Near-optimal probabilistic RNA-seq quantification. Nat Biotechnol. 2016;34(5):525-527. doi:10.1038/nbt.3519.

5. Fujioka N, Mukaida N, Harada A, et al. Preparation of specific antibodies against murine IL-1 ra and the establishment of IL-1ra as an endogenous regulator of bacteria-induced fulminant hepatitis in mice. J Leukoc Biol. 1995;58(1):90-98. 


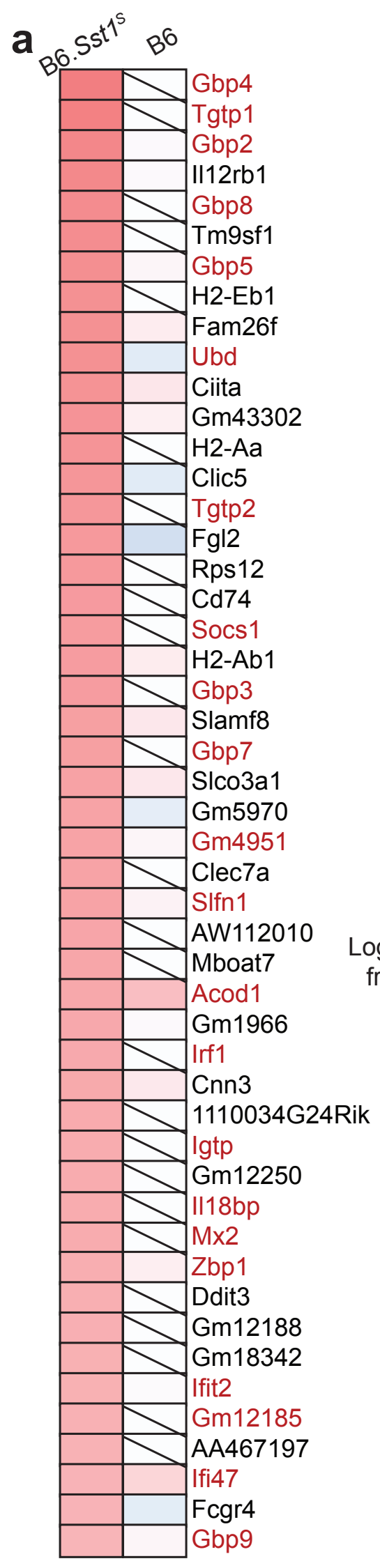
4.0 International license.

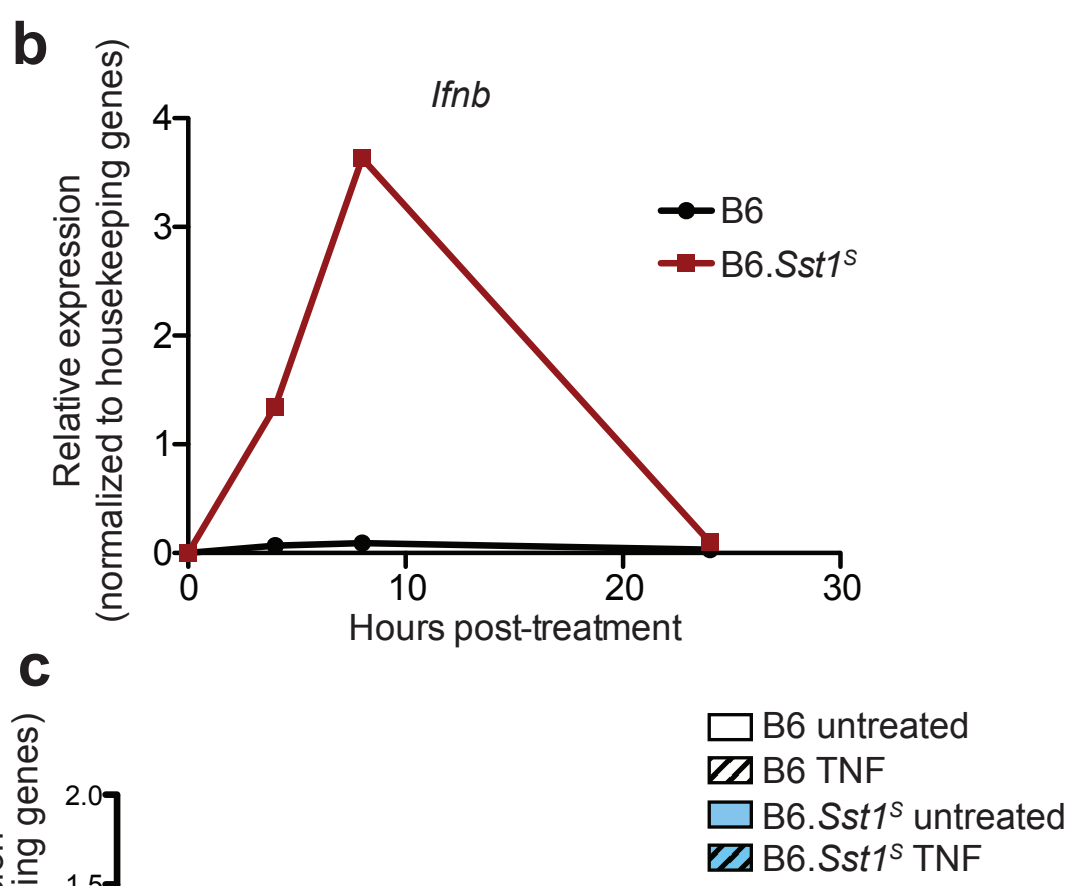

Log2 fold change

from untreated

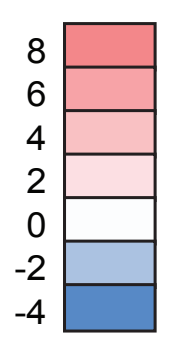

Not detected in untreated
or TNF-treated samples

Fig. S1 | B6.Sst1 ${ }^{\text {S }}$ BMMs overexpress Ifnb and ISGs when stimulated with TNFa. a, RNAseq results showing fold upregulation of ISGs in TNFa -treated versus untreated BMMs. 50 most upregulated genes in B6.Sst1' BMMs are shown. Known ISGs names are marked in red. b-c, Expression of Ifnb (b) or selected ISGs (c) in BMMs measured by RT-qPCR. Results normalized to housekeeping genes. Representative data of at least two independent experiments. 
bioRxiv preprint doi: https://doi.org/10.1101/389288; this version posted August 10,2018 . The copyright holder for this preprint (which was not certified by peer review) is the author/funder, who has granted bioRxiv a license to display the preprint in perpetuity. It is made available under

a

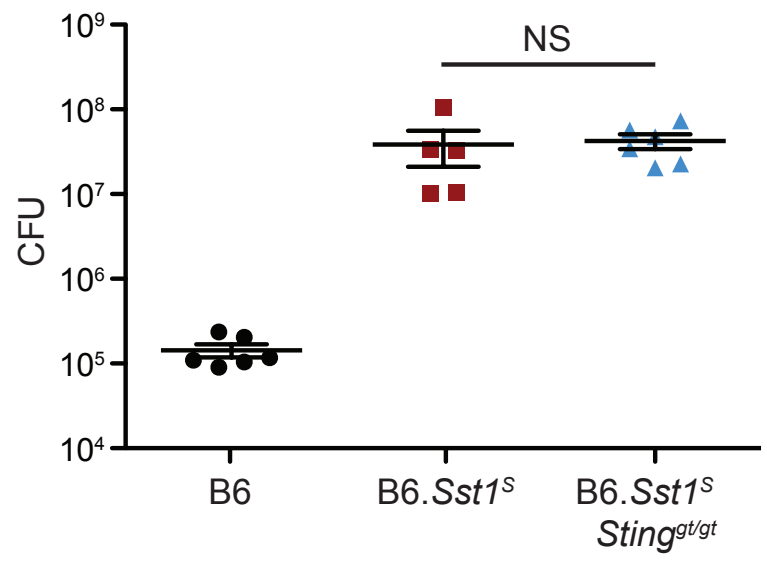

b

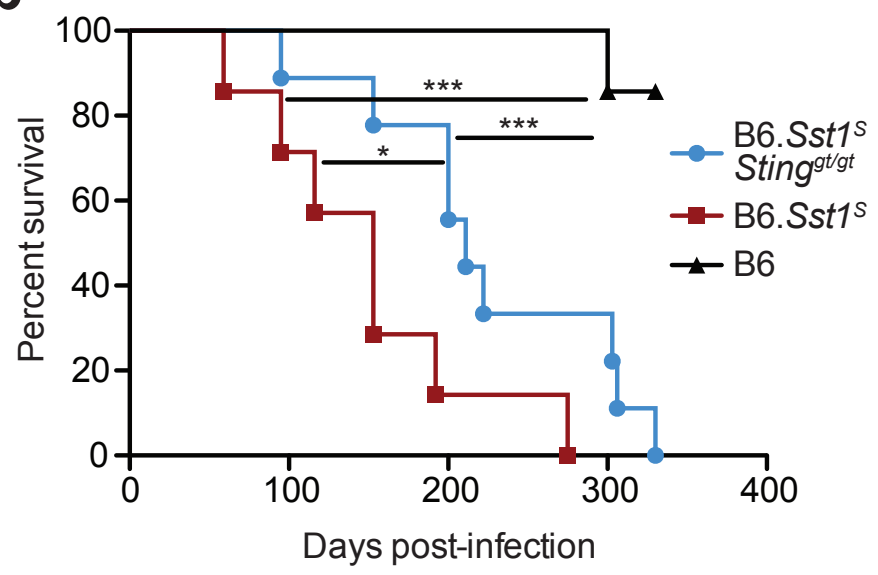

Fig. S2 | B6.Sst1 ${ }^{\text {S Sting }}{ }^{g t g t}$ partially rescues the enhance susceptibility of B6.Sst ${ }^{\text {s }}$ mice to Mtb. a, Lung bacterial burdens at day 25 (representative of two independent infections) or $\mathbf{b}$, Survival of mice infected with Mtb. All animals except B6 were bred in-house (a-b). Error bars are SEM. Analyzed with two-ended Mann-Whitney test (a) or Log-rank (Mantel-Cox) Test (b). Asterisk, $p \leq 0.05$; two asterisks, $p \leq 0.01$; three asterisks, $p \leq 0.001$. 
bioRxiv preprint doi: https://doi.org/10.1101/389288; this version posted August 10, 2018. The copyright holder for this preprint (which was not certified by peer review) is the author/funder, who has granted bioRxiv a license to display the preprint in perpetuity. It is made available under
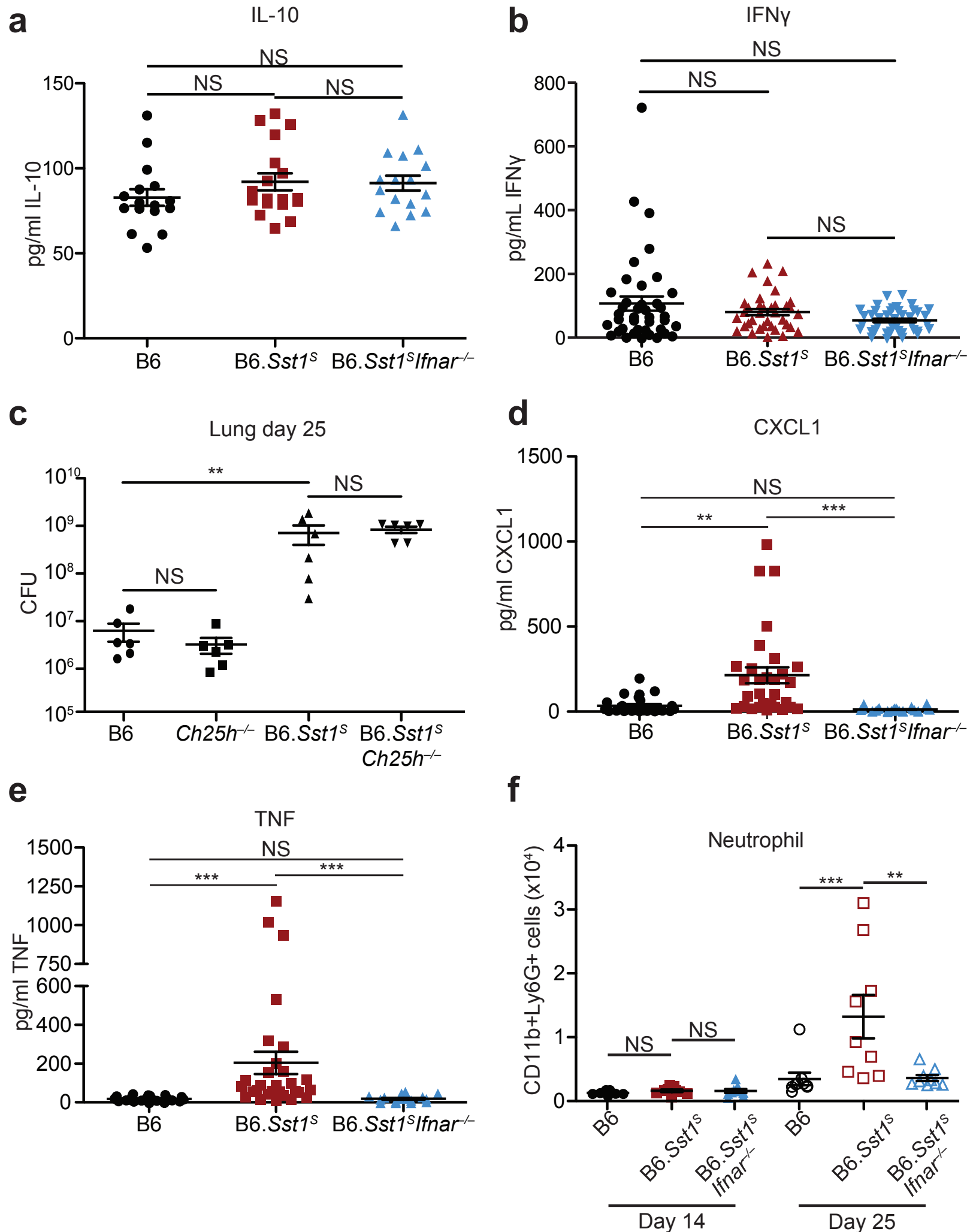

Fig. S3 | Enhanced inflammation in B6.Sst1s mice requires type I IFN but is not due to altered IL-10 or IFNy levels or Ch25h. a, b, d, e, Protein levels of IL-10 (a), IFNy (b), CXCL1 (d) and TNF (e) were measured in lungs of $M t b$-infected mice at day 25. Combined results of three independent infections. c, Lung bacterial burden of Mtb-infected mice at day 25 (representative of two independent infections). $\mathbf{f}$, Neutrophils $\left(\mathrm{CD} 11 \mathrm{~b}^{+} \mathrm{Ly}_{6 \mathrm{G}}{ }^{+}\right)$from lungs of $M t b$-infected mice were enumerated on day 14 and day 25. Combined results of two independent infections. All animals except B6 were bred in-house (a-e); all animals were bred in-house (f). Error bars are SEM. Analyzed with two-ended Mann-Whitney test (a-f). Asterisk, $p \leq 0.05$; two asterisks, $p \leq 0.01$; three asterisks, $p \leq 0.001$. 
bioRxiv preprint doi: https://doi.org/10.1101/389288; this version posted August 10, 2018. The copyright holder for this preprint (which was not certified by peer review) is the author/funder, who has granted bioRxiv a license to display the preprint in perpetuity. It is made available under

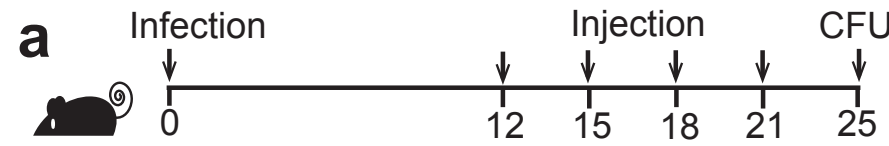

b
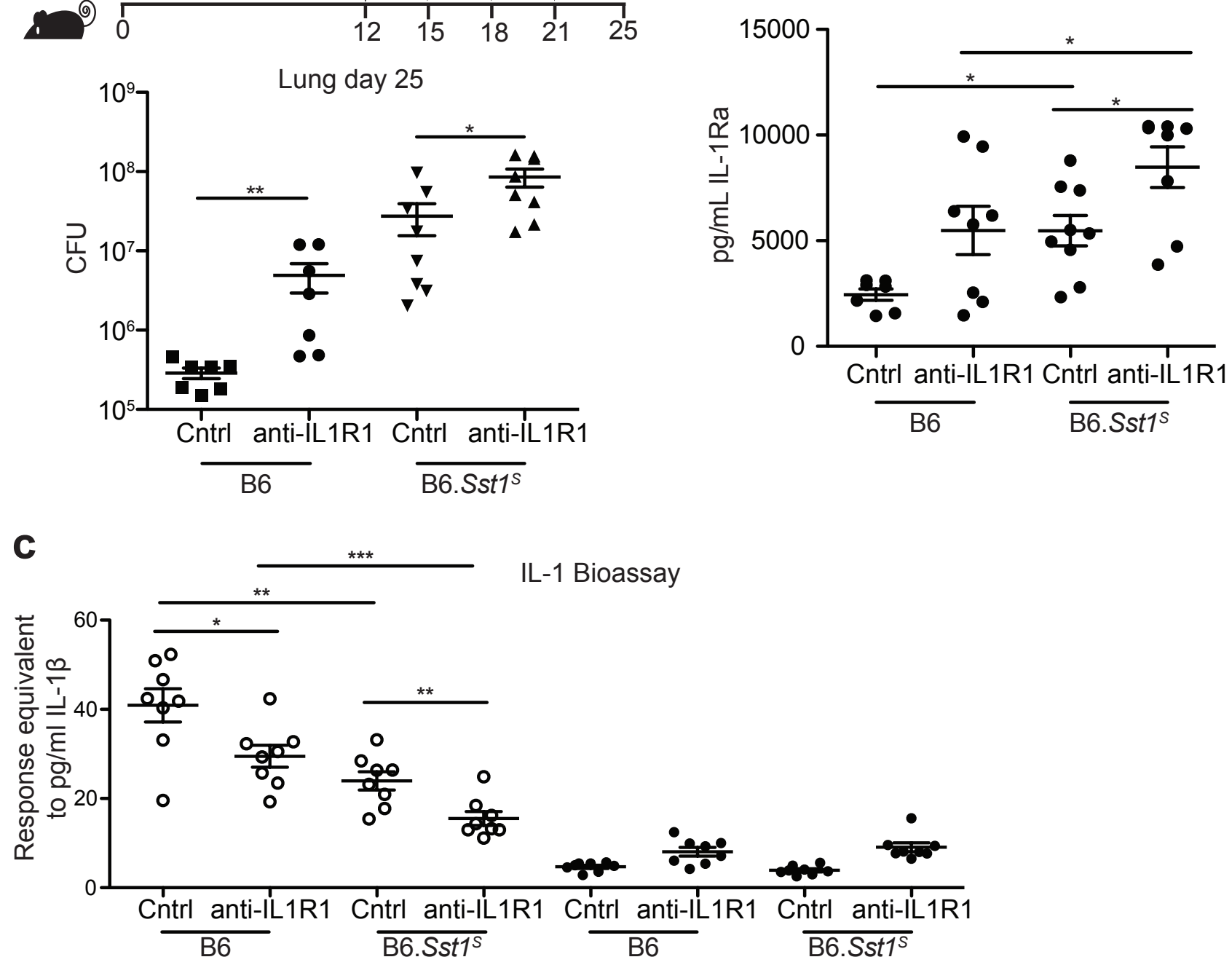

+ anti-IL1R antibody in assay

Fig. S4 | IL-1 blockade increases susceptibility in both B6 and B6.Sst1s mice. a-c, Mtb-infected mice were treated with anti-IL1R or isotype control antibodies, and on day 25 the lungs were measured for bacterial burden (a), IL-1Ra protein levels (b), and IL-1 bioactivity (c). All animals except B6 were bred in-house (a-c). Error bars are SEM. Analyzed with two-ended Mann-Whitney test (a-c). Asterisk, $p \leq 0.05$; two asterisks, $p \leq 0.01$; three asterisks, $p \leq 0.001$. 
a

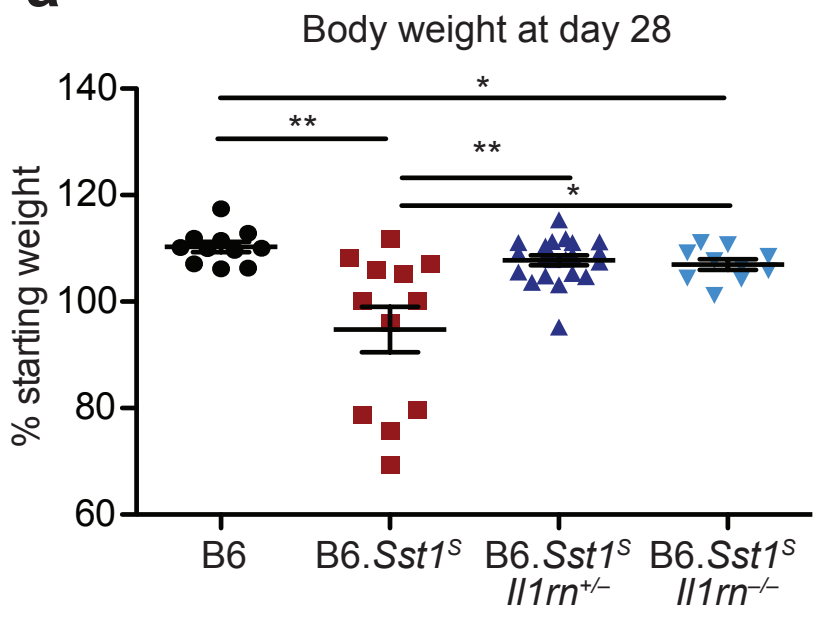

Fig. S5 | B6.Sst1s mice with homozygous or heterozygous I/1rn deletion retains more body weight at day 28 of $M$ tb infection than B6.Sst1s mice. Body weights on day 28 of individual mice shown in Fig. 4b. All were bred in-house, and all except B6 and B6.Sst ${ }^{S}$ were littermates. Error bars are SEM. Analyzed with two-ended Mann-Whitney test. Asterisk, $p \leq 0.05$; two asterisks, $p \leq 0.01$; three asterisks, $p \leq 0.001$. 